\title{
EL PRODIGIO DE ALEMANIA DE CALDERÓN DE LA BARCA Y ANTONIO COELLO: TEATRO Y PROPAGANDA POLÍTICA DURANTE LA GUERRA DE LOS TREINTA AÑOS
}

\author{
CALDERÓN DE LA BARCA AND ANTONIO COELLO'S \\ EL PRODIGIO DE ALEMANIA: THEATER AND POLITICAL \\ PROPAGANDA DURING THE THIRTY YEARS' WAR
}

\author{
Antonio M. Rueda \\ University of Washington \\ arueda@uw.edu \\ orcid: 0000-0002-8634-3842
}

\begin{abstract}
Resumen: El presente artículo examina la génesis de El prodigio de Alemania (1634), obra teatral de Calderón de la Barca y Antonio Coello que lleva a escena la destitución y posterior asesinato de Albrecht von Wallenstein, generalísimo del Sacro Imperio Romano Germánico acusado de conspiración durante la Guerra de los Treinta Años. La obra, representada unas semanas después del asesinato, se constituye como una respuesta a los inesperados acontecimientos que rodearon los últimos meses de vida del militar y que obligaron a intervenir a Felipe IV y al conde-duque de Olivares con el afán de no perder la reputación que habían alcanzado en los últimos años. El artículo propone que la obra nace con el objetivo de erigirse en defensa pública de Olivares y su política internacional, y de usar el teatro como arma de propaganda que convierta a un militar aplaudido por todos en un enemigo del imperio, cuya muerte servirá para mantener viva una contienda que supondrá el principio del fin de la influencia de España como potencia europea.
\end{abstract}

Palabras clave: El prodigio de Alemania; Wallenstein; conde-duque de Olivares; Calderón de la Barca; Guerra de los Treinta Años (16181648).

Abstract: This article examines the origin of El prodigio de Alemania (1634), a theatrical play by Calderón de la Barca and Antonio Coello that brings to the stage the dismissal and subsequent murder of Albrecht von Wallenstein, the generalissimo of the Holy Roman Empire who was accused of conspiracy during the Thirty Years War. The play, performed a few weeks after his murder, takes the form of an explanation of the unexpected events that surrounded the last months of the soldier's life and that forced King Philip IV and the Count-Duke of Olivares to intervene to avoid losing the good reputation they had acquired over the previous years. The article argues that 
the play was conceived as a public statement in defense of the foreign policy decisions taken by Olivares. Using theatre as a weapon of propaganda, the play turns a unanimously applauded soldier into an enemy of the empire and a figure whose death will be used to keep alive a struggle that meant the beginning of the end of Spain's influence as a European power.

Keywords: El prodigio de Alemania; Wallenstein; Count-Duke of Olivares; Calderón de la Barca; Thirty Years' War (1618-1648).

Recepción: 1 de octubre de 2019; aceptación: 22 de septiembre de 2020.

En 1634, España se encontraba involucrada en una larga guerra bajo la atenta mirada del conde-duque de Olivares. Dos años antes, el rey de Suecia había muerto en la batalla de Lützen a manos del ejército del Sacro Imperio Romano Germánico, liderado por el checo Albrecht von Wallenstein*. A pesar de que ninguno de los dos contendientes logró imponerse, los católicos celebraron la muerte de Gustavo Adolfo como una victoria. Antes de Lützen, el avance de las fuerzas protestantes amenazaba las regiones imperiales del sur de Alemania, pero en 1635 firmarían la Paz de Praga tras perder varias batallas más. La génesis y representación de El prodigio de Alemania, obra teatral de Calderón de la Barca y Antonio Coello, representada en 1634 y perdida desde entonces hasta comienzos del siglo XxI, se erige en objeto de estudio fundamental para alcanzar un conocimiento más profundo de la política internacional llevada a cabo por España durante la Guerra de los Treinta Años (16181648). La dramatización de la figura de Wallenstein es esencial para realizar este estudio por su labor como comandante general durante el enfrentamiento bélico y su carácter de protagonista en esta obra. La muerte del rey sueco supuso, paradójicamente, el principio del fin de la carrera de Wallenstein, y aunque el emperador Fernando II le agradeciera su rendimiento, el general terminaría siendo asesinado por militares imperiales. ¿Cómo es posible que se viniera abajo la carrera de un militar que tantos momentos de gloria proporcionó a las

* Este artículo no habría sido posible sin la inestimable colaboración de Henry W. Sullivan, catedrático emérito de literatura española de la Universidad de Tulane (EE.UU.). Desde que me presentara a Frislán/ Wallenstein en tierras bohemias, la relación no ha hecho más que crecer. A Sir Henry van dedicadas las siguientes páginas con la mayor gratitud. 
naciones católicas, el único a quien recurrió el emperador tras verse acorralado? ¿Cómo se representó esta caída en el teatro español de la época y, lo más importante, cómo se justificó en el contexto histórico en que tuvo lugar? El presente artículo responde a estas preguntas poniendo énfasis en la construcción propagandística de la dramatización de un hecho histórico que había ocurrido recientemente y en su función como proceso de legitimación para convencer a los espectadores de determinados intereses políticos e ideológicos.

La Guerra de los Treinta Años siempre tuvo como telón de fondo la supremacía del Imperio Romano Germánico ${ }^{1}$. La tregua firmada en 1609 había puesto fin a los enfrentamientos en los Países Bajos protestantes, pero tanto Felipe III como sus ministros eran conscientes de que la paz no podía continuar mientras se multiplicaran los ataques holandeses a colonias españolas. No había otro camino para España en 1621 que declarar la guerra a los Países Bajos. El monarca español había firmado antes el Tratado de Oñate, por el que daba su aprobación para que tras la muerte del emperador Matías tomara el poder su primo Fernando, a cambio de que éste garantizara acceso completo al "Camino español", red de territorios que permitía ir directamente desde Milán hasta los Países Bajos españoles. Aunque la guerra comenzó en el reducido espacio de Bohemia, el nombramiento de Fernando II como emperador en 1619 hizo que saliera de los confines bohemios y obligó a éste a pedir apoyo a España para defenderse de los intentos de usurpación protestante. Temeroso de perder su soberanía, Fernando II llamó a Albrecht von Wallenstein, noble bohemio que se había enriquecido con la confiscación de los Estados protestantes, para dirigir a los ejércitos imperiales ante el levantamiento del rey Cristian IV de Dinamarca. Uno de los territorios confiscados en Bohemia fue Frýdlant, que se convirtió en lugar de residencia y ducado personal de Wallenstein, de ahí que en España se lo conociera con el nombre de "Frislán". El bohemio consiguió reclutar a más de 50 mil hombres que se unieron a los ya comandados por el general Tilly —confederación inesperada por el rey danés, quien sufriría varias derrotas más-, y

${ }^{1} \mathrm{El}$ artículo hace uso de diferentes estudios históricos generales sobre la Guerra de los Treinta Años. Los más completos que he podido consultar y analizar con detenimiento son los de Geoffrey Parker, Peter H. Wilson, Cicely Wedgwood y Geoffrey Mortimer, mencionados en estas páginas y cuyas referencias se encuentran en la bibliografía. 
solicitó al emperador un tratado de paz en 1629 que llevaría la firma de Wallenstein ${ }^{2}$. En 1627, Olivares escribió al marqués de Aytona, quien servía de nexo entre él y Wallenstein en Viena, para preguntarle su opinión sobre el general; éste le respondió que no había conocido a un hombre tan leal y lo definió como amigo de los españoles y enemigo de los franceses (Elliott 1986, p. 333). El emperador proclamó el Edicto de Restitución en 1629 con la pretensión de restaurar el catolicismo en todas las regiones imperiales y de asegurar que su hijo Fernando fuera elegido como su sucesor. Sin embargo, necesitó el voto de electores temerosos de que Wallenstein pudiera intentar un golpe de Estado en Bohemia, por lo que pedirían su cese del cargo de generalísimo en la Dieta Imperial de Ratisbona en 1630 (p. 399). Enfadado por no haber tenido parecer en el asunto, Olivares consideró aquello un "terrible error" que podría traer consecuencias tremendamente perjudiciales a la Casa de Austria (p. 401).

El Consejo Real sueco declaró que había que entrar en guerra tras la proclamación del edicto (Ringmar 1996, p. 120) ${ }^{3}$. El saqueo de Magdeburgo, importante ciudad luterana, por parte de Tilly en mayo de 1631, propició que Gustavo Adolfo se enfrentara a las tropas imperiales en Breitenfeld en septiembre, batalla en la que los suecos arrasaron y que sirvió para que otros príncipes se unieran a su causa. En 1632, el rey sueco tenía en mente la destrucción del ejército imperial como método para asegurarse un futuro alejado del catolicismo, por lo que no dejó otra opción a Fernando II que pedir a Wallenstein que volviese a dirigir su ejército a sugerencia de Felipe IV y Olivares (véase Elliott 1986, p. 430). El 6 de noviembre se enfrentarían en Lützen para dirimir si el ejército protestante podría cumplir su cometido. Todo parecía marchar bien para los suecos hasta que la niebla hizo acto de presencia, eventualidad que aprovechó un soldado imperial para acercarse y acribillar al monarca

${ }^{2}$ Véase el capítulo que Parker (2006, pp. 49-57) dedica a la intervención danesa; WEDGwood (2005, pp. 203-38) analiza pormenorizadamente los motivos que llevaron a Cristián IV a participar en la guerra, así como sus relaciones con otros países invasores antes, durante y después de su intervención.

${ }^{3}$ Los católicos fueron expulsados de Suecia un año antes del comienzo de la Guerra de los Treinta Años, so pena de muerte para los que no se marcharan, y después de que un decreto real de 1627 permitiera el asilo en Suecia de protestantes perseguidos de otras partes de Europa. 
escandinavo ${ }^{4}$. En febrero de 1634, Wallenstein, el otro gran protagonista en Lützen, sería asesinado después de que las denuncias que lo acusaban de golpista se fueran acumulando sobre la mesa del emperador. Por ello, es necesario comprender las causas que dieron lugar a la necesidad de representar el declive de un héroe de guerra, con su sorpresiva demonización y clara intencionalidad política, en El prodigio de Alemania.

En 2001, Germán Vega García-Luengos publicó el primer artículo relacionado con la obra tras haber localizado una edición suelta olvidada durante casi cuatro siglos en la Biblioteca Nacional de Madrid. Por ser tan reciente el descubrimiento, esta obra no ha recibido todavía la atención que merece, sobre todo en lo que se refiere al origen de su concepción dramática. Su estudio nos puede dar luz sobre el funcionamiento de los mecanismos de poder y la capacidad del teatro áureo para favorecer la corriente ideológica dominante y la reputación nacional e internacional de la monarquía española. El recorrido histórico representado en El prodigio de Alemania comienza poco después de la batalla de Lützen, en algún momento entre el 17 y 18 de noviembre de 1632, y termina con la muerte del generalísimo Wallenstein durante la noche del 25 de febrero de 1634. Por consiguiente, los sucesos dramatizados transcurren en un tiempo histórico que corresponde al ecuador de la Guerra de los Treinta Años. La obra, aparte de escenificar los últimos meses de vida de Wallenstein desde la perspectiva imperial, nace como producto de la política internacional del gobierno de Olivares a mediados de la guerra, y se convierte en ejemplo de la utilización del teatro como medio propagandís-

${ }^{4}$ Véanse Parker 2006, pp. 121-122, y E.A. Beller 1971, p. 340. Fabricio Pons de CASTElví (1652) resumía la escena veinte años después y responsabilizaba de la muerte al exceso de confianza que padecía el monarca: "Veía ya Gustavo que estos felices sucesos se iban encaminando a la victoria, y deseando concluirla con chocar con todo el poder, por la parte donde los cesarianos estaban más flacos, se fue él mismo a reconocerlo de tan cerca que luego una bala de mosquete le castigó tan mal pensada temeridad, hiriéndole en el brazo izquierdo y llevándole a curar los soldados de su guardia... volvía a caso a la pelea una tropa de aquella nuestra caballería, que había huido (dichosísima fuga) y reparó también su afrenta que, acometiendo al rey, aunque con resistencia de los suyos, le mataron a pistoletazos, ignorando que matasen al más bizarro guerreador de nuestros tiempos, quedando al fin muerto y desamparado de todos el que quería ayudar a tantos... con autoridad de Pedro Bautista de Burgo, genovés y famoso cronista de las hazañas de Gustavo" (f. 110r-110v). 
tico para aumentar la reputación del régimen por su enorme difusión en todas las capas de la sociedad española de la época. El hecho de que Wallenstein fuese objetivo dramático de varias obras en España a principios de la década de 1630 lo transforma en una figura de sumo interés para los estudiosos del teatro español del siglo XVII. Henry Sullivan (2010) analiza estas obras protagonizadas por Wallenstein y las atribuye al interés de Olivares por celebrar las hazañas del general en una época en la que Viena había comenzado a sospechar que Wallenstein llevaba tiempo tramando algo en su contra.

El teatro promovido por Olivares proyectaba en la corte lo que estaba ocurriendo fuera de España, para que el rey y sus cortesanos pudieran ser testigos del éxito y reconocieran la defensa de los valores imperiales. La primera de las obras destinadas a glorificar la figura de Wallenstein le fue encargada a Lope de Vega, y se estrenó, conforme a lo que se desprende de una carta enviada por Bernardo Monanni — secretario del embajador de Florencia en Madrid-, el 29 de enero de 16335. El italiano escribe a propósito de una obra de Lope que califica de "gran comedia nuova che si faceva ne' soliti luoghi de' comedianti, della battaglia et morte del Re di Svezia" ${ }^{6}$. Monanni añade que la representación tuvo lugar en el Palacio de El Pardo y que desde las primeras horas del día hubo gente esperando para conseguir butaca en una sala en la que se encontraban Felipe IV y Olivares. Sin embargo, al día siguiente se emitió una orden del Consejo Real que prohibía su representación como consecuencia de la excesiva licencia tomada por el autor, y que Antonio de Mendoza, secretario del monarca, se encargó de corregir a partir de lo indicado en un nuevo aviso de Monanni ${ }^{7}$. Llama especialmente la atención que, según Monanni, en la obra original se hacían numerosos encomios del marqués de Santa Cruz y de Gonzalo Fernández de Córdoba, exceso que provocó los abucheos de un público descontento por la omisión de referencias a la actuación de Wallenstein en Lützen. En la versión corregida se multiplicaban las señas de valentía de Wallenstein, cambio que fue bien recibido por el monarca y detrás del cual, como

\footnotetext{
${ }^{5}$ Aunque hay diferentes referencias contemporáneas a la obra, se desconoce su título.

${ }^{6}$ Archivio di Stato di Firenze (en adelante ASF): Mediceo del Principato, t. 4959, f. 594; 29 de enero de 1633.

7 ASF: Mediceo del Principato, t. 4959, f. 600; 5 de febrero de 1633.
} 
de las demás modificaciones, es muy probable que se encontrara Olivares $(i d$.$) .$

La obra se representó el $1^{\circ}$ de febrero y, según la percepción de Monanni, "è molto tempo che non si è visto comedia haver tanta fama", a tal punto que no serán suficientes las representaciones antes del comienzo de la Cuaresma para satisfacer la demanda del público $(i d$.). A causa de este éxito prolongado y de los cambios que sufrió la obra, podemos afirmar que el pueblo conocía bien a Wallenstein y era consciente del papel heroico que se le atribuía en los triunfos españoles en Europa. Como indica Francisco Ruiz Ramón (1971), lo más importante en los dramas históricos del teatro áureo es

destacar, con ejemplaridad ideal, mediante las situaciones interesantes que la historia suministra, la dimensión heroica del pasado nacional. Por ello los héroes de este teatro cambian de nombre, pero no de esencia, pues, en realidad, no hay más que un héroe: el heroísmo (pp. 236-237).

En medio de toda esta exaltación, Calderón se encargaría de satisfacer los deseos de aquellas personas que deseaban ver sobre las tablas la consecución de esos grandes triunfos y vitorear a sus heroicos responsables.

La batalla de Breda en 1625 es la de mayor renombre durante los treinta años de conflicto, cuya victoria sobre los holandeses a manos del general Spinola se dedicaron a celebrar autores como Lope, Calderón o Velázquez. José María Díez Borque (2001) indica que el teatro español del Siglo de Oro "pone la historia al servicio de la causa" y que, durante la guerra,

se escribieron obras teatrales para conmemorar hechos históricos concretos, dando a la puesta en escena un carácter de celebración y enfocando la historia desde la perspectiva exaltadora... Éstas serán las coordenadas del teatro español referido a la Guerra de los Treinta Años, que festejará las victorias y olvidará las derrotas y la marcha general de los acontecimientos (p. 186).

Los palacios, como el del Buen Retiro o El Pardo, eran lugares donde se concentraban cuadros, representaciones teatrales y entradas triunfales en celebraciones que alababan las grandezas de España, y cuya interpretación oficial del régimen se pretendía diseminar apologéticamente entre los asistentes. Después de recibir las noticias de lo ocurrido en Breda, Olivares 
escribió una carta a Carlos Coloma en la que explicaba su concepción de victoria: "Para mí no hay día ni sucesso bueno sino aquel que conserva y adelanta la reputación de las armas y de la grandeza de su majestad... Señor mío: coraje y cóbrennos respeto los enemigos de Dios". Tres días después, el 8 de julio, le informaría: "El día de San Felipe y Santiago se recobró el Brasil con muy gran reputación de las armas de Su Majestad" (Rodríguez Villa 1904, pp. 433-434).

La tarea del autor a la hora de plantearse cómo representar un episodio histórico consistía, según Kurt Spang (1998), en "transformar y «rellenar» los acontecimientos históricos de tal forma que destaque la ejemplaridad y, por así decir, la «supraindividualidad» del hecho singular" (p. 14); en definitiva, en edificar una representación "estéticamente ordenada de situaciones documentables a caballo entre la ficción y la referencialidad; una construcción dirigida por un determinado autor a un determinado público en un determinado momento" (p. 26). El teatro se transformaba así en una poderosa influencia que pretendía escribir o reescribir la historia, transportar las noticias recientes a los corrales de comedias y dejar constancia de la notoriedad de sus grandes personajes para las generaciones presentes y futuras. Juan Matas Caballero (2015) indica, en referencia a los dramas históricos en el teatro del Siglo de Oro, que éstos tienen "como misión intrínseca la intención de ofrecer una reflexión crítica, didáctico-moralizante e ideológica, sobre su tiempo presente" ${ }^{8}$. El prodigio de Alemania se concibió tras varios triunfos recientes en diferentes partes del mundo, y ejemplifica la obsesión de Olivares por la reputación y la mediación entre el pasado y el presente mediante la creación de útiles modelos capaces de cumplir con directrices educativas encaminadas a la difusión de la ideología que pretendía extender. Además, como se demuestra en las páginas siguientes, esta obra se convierte en un caso que modifica las características esenciales de este tipo de representaciones como consecuencia de la necesidad de expre-

${ }^{8}$ Lope DE VEGA también era muy consciente de esa capacidad que tenía el teatro, por encima de la letra impresa, para presentar una cultura dirigida a fines específicos y mediante el drama histórico, como explica en la dedicatoria a La campana de Aragón en 1623: "la fuerza de las historias representada es tanto mayor que leída, cuanta diferencia se advierte de la verdad a la pintura, y del original, al retrato... nadie podrá negar que las famosas hazañas referidas al vivo con sus personas no sean de grande efecto para renovar la fama desde los teatros a las memorias de las gentes" (f. 298r-298v). 
sar la impredecible y cambiante actualidad política en Europa, así como la conflictiva concepción de unidad nacional.

El prodigio de Alemania se dispone dentro de un conjunto de obras teatrales cuyas tramas tienen lugar en Bohemia durante la guerra. Anteriormente, Olivares había encomendado una obra a Calderón y Coello en la que se escenificaba la muerte del rey de Suecia, y de la cual sabemos por referencias contemporáneas de algunos de los que asistieron a sus representaciones. Monanni presenció una de ellas el 4 de marzo de 1634, una semana después de la muerte de Wallenstein, que ensalzaba las virtudes del checo en el campo de batalla en Lützen, al igual que se celebraba en la escrita por Lope de Vega un año antes:

Si compose per due gran poeti qui unitamente, Calderon e Cuello, una commedia che rappresenta le prodezze del duca di Frisland, e prima di recitarsi, come è gia seguito più volte dai comici pubblici, perchè trattava di principi viventi, acciò non si offendesse nessuno, e non si narasse cosa all'uso poetico, troppo lontano dalla verità, $\mathrm{fu}$ fatta rivedere dal Consiglio di Stato, e in fine approvata. Ha dato gran gusto per il buon modo con que rappresenta le fazzioni di guerra, e in particolare la rotta del Rè di Suezia, celebrando il suo valore... Del Frisland poi parla con gran decoro, mostrandolo formar squadroni, dar ordini militari, batterie, assalti, battaglie, rotte, stragi e ogni notabile e valoroso successo vero o verisimile: sopratutto lodando sempre, non dicendo male di nessuno. Solamente si è osservato che non nomina mai... il Rè di Francia nè Francese alcuno (Justi 1888, t. 1, p. 345) ${ }^{9}$.

Llama la atención que el florentino recalcara que en la obra no se hablaba mal de Francia o de su rey, ni por supuesto del Cardenal Richelieu, gran enemigo de Olivares. Matías de Novoa — ayuda de cámara y biógrafo del monarca español— incluso señalaba en su Historia de Felipe IV (ca. 1647) que, tras la victoria en Lützen, los franceses

se cubrieron de mortal melancolía por el buen suceso que había conseguido el César, por la alegría de España, y porque en algunos

9 Véanse Cotarelo y Mori (1924, pp. 149-150) y Vega García-LuenGOS (2001, pp. 793-794). La mayoría de estas fuentes, incluidas las más modernas, ha reproducido la cita repitiendo el error de Justi de considerar al embajador Averardo de Medici - "commendatore di Sorano", es decir, de la localidad de Sorano, en la Toscana- el autor de estos informes, y no a Monanni. Véase Brown \& Elliott 2003, p. 260. 
años no había tenido nueva más bien afortunada para toda la cristiandad... pero el francés... no aflojó un punto en persistir a la sedición y a la ruina de todo (1878, p. 245).

La muerte de Gustavo Adolfo sirvió a Richelieu para convencer a los Estados perjudicados por los avances imperiales de unirse a ellos. A comienzos de 1634, Felipe IV escribía al conde de Oñate — representante de España en Viena- con el propósito de pedirle ayuda en la creación de una unión que se había de procurar "con todo secreto" para defenderse de un ataque que se suscitaría próximamente (Günter 1908, p. 406) ${ }^{10}$. Si se estaban llevando a cabo negociaciones, cabe la posibilidad de que, teniendo en cuenta que Calderón y Coello habían recibido el encargo de encumbrar a Wallenstein, cualquier alusión negativa a Francia podría dar lugar a que un embajador o espía francés sospechara de lo que se estaba planeando tras la muerte del rey de Suecia ${ }^{11}$. Por tales motivos, tampoco se hará mención alguna de este país en El prodigio de Alemania. En España se conocía sobradamente que los franceses ayudaban a los Estados protestantes en su lucha contra el imperio desde hacía ya varios años, y el temor a que Francia entrase en la guerra era evidente, como informaban los embajadores españoles esparcidos por el imperio ${ }^{12}$.

10 “[S]e entiende que el rey de Francia está resuelto a romper la guerra con el imperio y conmigo en Flandes, Alemania y Italia... Y así conviene... que vos procuréis luego con todo secreto y por los medios más eficaces que os parecieren asentar la liga con el emperador contra el rey de Francia recíprocamente y que se engruese el ejército del duque de Feria..., que no puedo dejar perdidos hoy todos los estados de Flandes... Y en caso que el emperador desamparase esta causa, trataréis... que entre en Francia a mis órdenes otro ejército poderoso fuera del duque de Feria" (31 de enero de 1634; GÜNTER 1908, p. 406). Las cartas de Felipe IV han sido extraídas de la colección de documentos del Archivo de Simancas, agrupadas por Heinrich Günter en Die Habsburger-Liga 1625-1635.

11 Vega García-Luengos señala: "que los embajadores franceses eran hombres a los que determinadas alusiones del teatro español de la época les podían agraviar queda claro en otro testimonio cercano en el tiempo, donde el afectado... es Nicolás de los Ríos. Por un escrito firmado en Valladolid en septiembre de $1601 \ldots$ se le había prohibido el año anterior que actuase en Madrid... por haber molestado al diplomático del país vecino con una de sus representaciones" (2012, p. 48).

${ }^{12}$ Diego Saavedra Fajardo, embajador en Baviera, informó el 4 de febrero de 1634 al cardenal infante Fernando que los franceses habían puesto "la mira en las cosas de Alemania, conociendo que en la presente perturbación 
En una nueva carta de Felipe IV a Oñate del 28 de febrero de 1634, tres días después del asesinato del duque, del que no se tenía constancia en Madrid, el rey insistía en convencer a Wallenstein de unirse a la creación de una liga antifrancesa:

En otro despacho os digo las formas en que os habéis de gobernar en las cosas del duque de Fritland, y que en caso de no negociarse con él lo que ya se os ha dicho [que formase parte de la liga contra Francia], será bien reducir la asistencia de dinero a gente pagada. Vos y el marqués de Castañeda dejaréis obras al emperador en las cosas del duque sin arrimar a una parte ni a otra, salvo quando viéredes que se aventura el todo y que hay medio para poderlo atajar. Y si este caso llegare y fuere contra Fritlant, será bien advertirle y referirle todo lo que yo he hecho por él y he mandado que se haga, sin que en tantos años haya él ejecutado ninguna cosa en favor de mis conveniencias, siendo éstas y las del emperador unas mismas (Günter 1908, pp. 407-408).

El monarca español pedía a Oñate que defendiera a Wallenstein, si fuera necesario, en caso de que el emperador "fuere contra Fritlant", a pesar de que Oñate le había advertido que Wallenstein estaba en contacto con Richelieu, según un informante cercano al emperador ${ }^{13}$. Dos meses antes, el 29 de diciembre de 1633, Oñate había escrito al monarca para darle su certera opinión sobre los últimos actos realizados por Wallenstein, señalando que éste "no hubiera podido obrar más contra su servicio [del emperador] de lo que ha hecho este año" (p. 463). Por lo ocurrido en los dos primeros meses de 1634, se entiende que Felipe IV no confiaba plenamente en la opinión de Oñate y que tenía gran fe en lo que podía lograr el

del Imperio pueden a poca costa, comprando unas plazas a dinero de los suecos y ocupando otras con la fuerza, extenderse por estas provincias... éste es el medio más cierto para destruir la Monarquía de Su Majestad, porque con Alemania se pueden sustentar Flandes y Italia, y sin ella, se pierde todo" (Aldea Vaquero 1986, t. 2, p. 24).

13 "Esta persona dice saber con evidencia que el 10 de septiembre pasado, tuvo audiencia de más de tres horas del rey de Francia y Cardenal de Richelieu solos una persona enviada por el Duque de Friedlant, sin que se haya podido penetrar lo que trató... He sabido que el deseo de Friedlant de echar al Duque de Feria de Alemania y deshacer sus tropas llegó a escribir duplicadas veces al Duque de Baviera que llame Aldringuer, a quien ordenó que por ningún accidente ni de ninguna manera pisase el Ducado de Wirtembergh, siendo el único país en toda Alemania donde estas tropas del mismo Aldringuer y del Duque de Feria podían rehacerse” (ibid., p. 462). 
checo, pues, a finales de febrero, y con bastante desesperación, aún esperaba su visto bueno. Ésta también era una de las razones por las que, a pesar del retrato de Wallenstein dibujado por Oñate, tanto Felipe IV como Olivares anhelaban que aceptara sus propuestas; de ahí la imagen positiva de éste en la obra perdida. En otra misiva enviada el 28 de febrero de 1634 a Oñate, el monarca le recordaba: "aunque debe dar mucho cuidado la extravagancia de sus acciones... ni es justo condenarlas sin oírle... cuando las culpas fueran declaradas" (p. 407) ${ }^{14}$.

El teatro se había convertido en instrumento de difusión de noticias, por medio del cual las autoridades gubernamentales informaban lo que estaba ocurriendo fuera de España ${ }^{15}$. El prodigio de Alemania fue una de las últimas obras cuya trama giraba en torno a la acción de la guerra europea, ya que, después de ésta, las derrotas se fueron acumulando, con escasas excepciones, hasta 1648. Calderón escribió El sitio de Bredá casi al mismo tiempo en que se iban produciendo los acontecimientos, y se representó antes del 5 de noviembre de 1625, no más de cuatro meses después de la toma de Breda (Whitaker 1978, p. 519) ${ }^{16}$. Es posible incluso que la obra se estrenara en agosto, según se desprende de una carta enviada por el embajador de Toscana en Madrid, Averardo de Medici, a la corte Medici el 31 de agosto, en la que precisa que hacía dos semanas que se venía representando ${ }^{17}$.

${ }^{14}$ Los jesuitas acusaron también a Wallenstein de tener intereses comunes con Francia. En carta redactada el 28 de marzo de 1634, tres días después de conocerse en Madrid la muerte de Wallenstein, el padre Francisco Vilches informaba al padre Rafael Pereyra del deceso y acusaba al checo de haber "hecho contrato con el [rey] de Francia... había de entregar los ejércitos en manos de Francia, todo a fin de destruir la casa de Austria. Que el de Francia había de ser rey de romanos... al duque de Frisland le daban los estados de Flandes con título de rey de Flandes" (Cartas de algunos padres de la Compañia de Jesús... 1861, t. 1, p. 29).

15 Véanse Alenda y Mira 1903, t. 2, p. 287, y Díez Borque 2001, p. 193. Debido a esa capacidad de las artes escénicas, Calderón escribió, a petición de Olivares, Diálogo de la guerra y la paz como parte de un conjunto de acontecimientos organizados durante el Carnaval de 1637 para celebrar la elección de Fernando III como emperador en el Palacio del Buen Retiro de Madrid. La celebración servía también para demostrar a los franceses que había dinero con que continuar la guerra, y que la llegada al trono del vástago renovaba las fuerzas de un enfrentamiento que cumplía ya dos décadas.

${ }^{16}$ El 15 de junio llegaron las noticias de la victoria a Madrid.

17 "Si è messo in commedia la presa di Breda et da due settimane in qua si recita ogni giorno con grande aplausso et concorso di tutta la Corte. Il 
La ausencia de acción bélica en El prodigio se debía fundamentalmente a que la preparación de un escenario más detallado alargaba el estreno de una obra que necesitaba, desde su concepción, una representación apresurada, al contrario de lo que había sucedido con la obra estrenada en marzo y que incluía escenas bélicas montadas con detalle, según la descripción de Monanni. Con base en la definición de literatura política durante la Guerra de los Treinta Años ofrecida por María Soledad Arredondo (2011, p. 73), ésta "nace con la finalidad no sólo de comunicar unos hechos, sino también de defender una tesis y de neutralizar y rebatir ideas, imágenes o palabras previas del adversario". En el caso de El prodigio podemos usar esta definición, pero desde una perspectiva diferente. Con esta obra se creaba una situación paradójica en la cual la representación dramática, gestada a dictado del propio poder, proponía una neutralización que no tenía su razón de ser en ideas difundidas por el adversario, sino en una obra engendrada, poco tiempo antes, por las mismas personas que después se encargarían de diseñar su enmendada respuesta. Por este motivo, el carácter propagandístico de la obra tomaba un carácter urgente -se hacía necesario rectificar la historia que se había defendido públicamente-, hecho que demostraba que la guerra ideológica se estaba disputando también en los escenarios. El teatro calderoniano se involucraba directamente en la representación de los conflictos bélicos y servía de reflejo de una realidad histórica cercana a los ideales de los poderes políticos.

El prodigio de Alemania se divide en tres actos o jornadas cuyo orden de impresión no sigue un criterio cronológico lineal: los dos primeros actos se han invertido en la suelta original, de modo que la jornada segunda corresponde al primer acto y la jornada primera al segundo. Puede ser que la premura de los autores tenga relación con este desorden en la suelta original, aunque se desconoce cuándo se imprimió. Es de suponer que, si Calderón pudo escribir El sitio de Bredá en un período inferior a cuatro meses, los dos autores, al trabajar en equipo, se habrían dado mucha más prisa para corregir el texto anterior que elogiaba la figura de Wallenstein. Su caída tenía que

compositore fra l'altre cose rappresentava nella scena il tentativo fatto dalli olandesi di entrare nel quartiere delli italiani, ponendo la fazzione della difesa in persona della nazione spagnuola, il che saputosi dal Re volse che si rappresentasse la pura verità et si desse a ciuascuno il suo onore" (ASF: Mediceo del Principato, t. 4953, 31 de agosto de 1625). 
resultar convincente y debía presentarse en el escenario tal y como se había hecho en las obras precedentes con su gran poderío en el campo de batalla. El 26 de marzo llegaron las noticias de Viena anunciando la muerte de Wallenstein, con lo que, en algún momento del mes de mayo o a principios de junio, podría haberse representado la obra, máxime si tenemos en cuenta que la última escena presenta el nombramiento de Fernando III como nuevo generalísimo imperial, suceso histórico que tuvo lugar a finales de abril.

La jornada primera comienza con la aparición del capitán De Bros, oficial de Wallenstein, que va de camino a la corte de Viena para informar al emperador de lo sucedido en la batalla de Lützen: "no se lee más gloriosa, / ni en crónicas de España / ni en los anales de agora" (vv. 28-30) ${ }^{18}$. Al precisar el capitán que hay que informar al emperador de "la muerte / del de Suecia" (vv. 21-22), el espectador puede situar el presente histórico de la obra y reconstruir el pasado a partir de la información que conozca sobre lo ocurrido en dicha batalla. Tal reconstrucción tendrá que modificarse conforme avance la obra, pues el acontecimiento que la cierra - la muerte de Wallenstein- no ocurre sino hasta 16 meses después del comienzo, si consideramos el tiempo histórico. Por ello, me inclino a pensar que hay partes de El prodigio - al principio, particularmente- que elogian los servicios de Wallenstein, las cuales bien podrían haber estado presentes en la obra perdida y representada antes de cualquier noticia sobre su muerte, y en la que sabemos, por la carta de Monanni citada arriba, que se habla "con gran decoro" del general.

Es muy poco lo que se conoce del capitán De Bros más allá de que su personaje está basado en Walter Devereux, oficial irlandés, y que su nombre, como sucede con otros personajes de la obra, ha sido hispanizado. En la obra, por su función de ejecutor de Wallenstein, toma un mayor protagonismo del que realmente tuvo en la conspiración para acabar con la vida del general. Wallenstein se dirige a Viena acompañado por tres de sus oficiales: el Mariscal, Tersa y el coronel Cordón. El personaje del Mariscal está basado en Christian von Ilow, militar ascendido a mariscal de campo por el propio Wallenstein; Tersa

18 Todas las citas de los versos de la obra están tomadas de la edición crítica de Antonio M. Rueda (cf. CALderón y Coello 2014), la única realizada hasta la fecha. 
representa al conde Trčka, cuñado de Wallenstein; y Cordón correspondería al coronel John Gordon, imperialista y gobernador de la plaza fuerte de Egra. El general pronuncia dos largos parlamentos en la obra, a manera de monólogo, utilizados por los autores para presentar el recorrido histórico del personaje y recrear los supuestos motivos por los que después querrá rebelarse. Según lo señalado por Florencia Calvo (2002) sobre la función de los monólogos en los dramas históricos, éstos sirven para organizar la estructura cronológica de la obra y definir los núcleos de la acción argumental: "permiten en el nivel de la recepción que el público se familiarice con los hechos históricos, los actualice si los conoce pero no los recuerda y, lo que es más importante, participe del mismo tipo de selección de la materia histórica que ha realizado el dramaturgo" (p. 212).

En el primer parlamento (vv. 608-647), Wallenstein muestra deseos de venganza contra el emperador por haberlo cesado de su puesto de generalísimo. Podemos conjeturar que esta parte no se encontraba en la obra anterior y que fue añadida por los autores para simplificar los motivos de Wallenstein, de modo que el público pudiera entender que la rebelión se debía al rencor que guardaba todavía después de varios años. De cualquier modo, como veremos a continuación, Calderón y Coello presentan hechos históricos que se corresponden con lo sucedido en los últimos años de Wallenstein. Estas atribuciones fortalecen la idea de que seguían órdenes de Olivares para dar a entender en la obra que Wallenstein actuó así porque no había olvidado su cese, línea argumentativa por demás simplificadora a la que aludíamos antes. El comienzo de El prodigio avanza in medias res, por lo que la información histórica que se presenta en estos monólogos hará más comprensibles los deseos de venganza de Wallenstein y suscitará una relación de cercanía con el espectador entre el momento de la representación y el episodio histórico representado que establece la contemporaneidad de las características discursivas de la materia dramatizada.

La acción de la obra también se desarrolla en la corte imperial, donde el capitán presenta un largo parlamento para relatar al emperador lo ocurrido en Lützen y elogiar el comportamiento de Wallenstein, así como la valentía del rey de Suecia. Como señalaba Monanni en referencia a la obra perdida sobre Wallenstein estrenada en los primeros días de marzo de 1634, en la que destacaba el valor con el que se representaba al monarca sueco, De Bros hace justamente lo mismo en este parlamento 
delante del emperador: "Que aunque nombro a tu enemigo, / con admiración lo nombro, / porque hace el vencido fuerte / al vencedor más glorioso" (vv. 885-888). La admiración que expresa hacia Gustavo Adolfo se corresponde con la descripción del florentino, por lo que es posible que los autores tomaran este parlamento de la obra perdida, donde se alaba también la actitud valerosa de Wallenstein en la batalla, al considerarlo "el rayo de Alemania" que acabó con "el de toda Europa asombro" (vv. 879-880). La admiración por el vencido es una característica que ya había aparecido en otras obras de Calderón como cualidad intrínseca de militares y nobles hispanos, que aumenta la proyección de la imagen propia y fortalece su reputación.

Al contrario de la obra sobre Breda, en que la batalla tiene lugar durante la acción dramática, en El prodigio de Alemania el enfrentamiento no se representa, sino que aparece descrito en las palabras del capitán, quien hace mención de las bajas para informar al emperador: "murieron del de Suecia doce mil hombres y sólo / tres mil de tus imperiales" (vv. 1051-1053), números en los que Calderón y Coello se acercan a la realidad de lo ocurrido y confirman el acceso directo que tuvieron a las fuentes oficiales para poder componer su obra (Rueda 2012, p. 99) ${ }^{19}$. Sin embargo, a pesar de que el checo no visitó la corte imperial en la década de 1630, el primer acto termina con su llegada y un efusivo recibimiento del emperador ${ }^{20}$. Fernando II ratifica su confianza en él, la misma que tenían los españoles cuando se llevó a cabo la representación de la obra perdida y que podría relacionarse con su presencia en ella: "aunque alguno ha pretendido / derribar nuestra amistad, / nunca de vuestra lealtad / traición mi pecho ha creído, / como creerlo, es locura / el pensarlo solamente" (vv. 1165-1170).

Wallenstein ofrece en el segundo acto el parlamento más largo de la obra, en que define su identidad por medio del recuerdo de su pasado militar hasta la victoria en Lützen.

19 VANesa Fortuño (2005, p. 256) también señala que Calderón utilizó la sugestión y evocación de las batallas, en vez de la representación directa de éstas, en varios dramas históricos como El segundo Escipión y Las armas de la hermosura.

${ }^{20}$ MAnN (1976, pp. 633-634) indica en su biografía que Wallenstein no visitó la corte en los cinco años anteriores a Lützen y que pagaba enormes sumas de dinero a sus correos para que entregaran la correspondencia al emperador en Viena. Beladiez (1967, p. 354) señala además que Wallenstein nunca se presentó en la corte imperial después de Lützen. 
Considerando que El prodigio de Alemania comienza in medias res, que no representa ninguna de las batallas en las que luchó Wallenstein y que se centra en su intento de golpe de Estado, el parlamento es la herramienta de contextualización histórica mediante la cual los espectadores actualizan su conocimiento sobre el general hasta el momento en que está siendo representado en el escenario - desde la perspectiva oficialista seguida por los autores-y lo sucedido en la primera mitad de la guerra. La autobiografía se presenta como "mis blasones" (v. 1462), es decir, los motivos por los que el personaje ha ido ganando fortuna y respeto; la construcción de una compleja identidad ahora se magnifica en detrimento de la causa imperial. Wallenstein defiende una carrera labrada a base de esfuerzos y se enorgullece de haber atraído la admiración del emperador, hecho que le llevó a conseguir su primer título de nobleza -Príncipe de Bolestán - tras haber defendido los territorios imperiales a fines de la década de 1620. La única explicación que el checo encuentra a su cese es la envidia de hombres cercanos al emperador: "Mas la envidia, / que al abrigo / del ocio infame se acoge / a fraguar viles defectos / y en las más puras acciones / su diente armó venenoso / contra mi fama, creyoles / Fernando, y en mengua mía / lisonjeó a los traidores" (vv. 1543-1550).

El Wallenstein que se representa en la obra es, en gran medida, el producto de aquellas acciones anteriores a la batalla de Lützen, siempre presentes en el discurso que elaboran los autores, con el propósito de mostrarnos que la venganza será el motor del plan que presentará a sus oficiales. Los "traidores" que menciona eran los príncipes alemanes cercanos a Maximiliano I de Baviera, quien hasta ese momento tenía el ejército más poderoso del imperio y veía cómo Wallenstein recibía privilegios del emperador a raíz de sus triunfos. Como señala Golo Mann (1976) acerca del cese en la Dieta de Ratisbona en 1630, "the target at Regensburg was not the real Wallenstein, the man above party who in the no-man's-land of his untrammeled intelligence had tried to pursue a policy beyond his strength, but an abstraction, the personality imagined in the plots and counterplots of the powers" (p. 524). Es ésa precisamente la personalidad wallenstiniana que se representa en El prodigio, la de un hombre que olvidó sus valores militares para emprender un plan que pretendía trastocar la estabilidad imperial.

Calderón y Coello introducen este deseo de satisfacción del duque antes de aludir al nuevo llamamiento del emperador. La 
situación del territorio imperial había empeorado tanto que, ya en mayo de 1631, Fernando II escribió personalmente a Wallenstein para pedirle que regresara a Viena, a lo que éste hizo oídos sordos hasta la derrota del general Tilly en la batalla de Breitenfeld el 7 de septiembre. Los suecos siguieron avanzando y el 15 de noviembre tomaron la ciudad de Praga. La cercanía a los territorios de Wallenstein fue la causa de que el general acordara su regreso al cargo a finales de 1631; y en abril de 1632 no sólo recibió toda la autoridad militar que necesitaba, sino también la potestad para negociar con el enemigo (Mortimer 2010, p. 132; Beller 1971, p. 336). El parlamento se esfuerza por presentar a un Wallenstein cuya motivación para regresar a dirigir el ejército imperial se fundamenta en sentimientos rencorosos y de satisfacción individual más que en respeto a las órdenes imperiales, como sí se daba a entender en el parlamento del capitán y las palabras que intercambia con el emperador al final del primer acto:

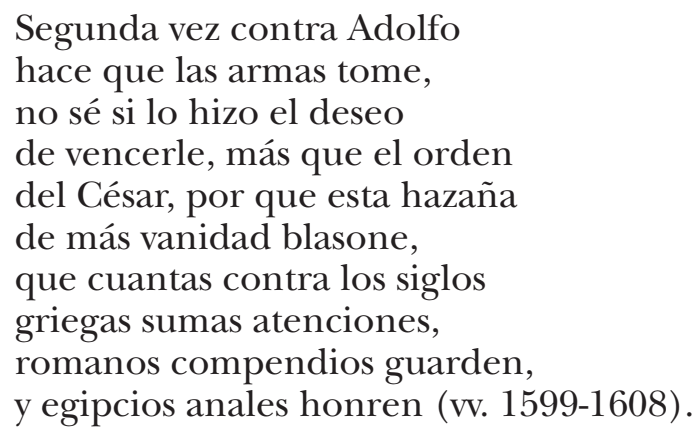

A partir del momento en que recuerda su regreso, el parlamento de Wallenstein se convierte en una afirmación exclusiva del yo, es decir, una loa de su carrera militar que lo coloca en un lugar de preeminencia con el propósito de convencer a sus oficiales para que lo acompañen hasta las últimas consecuencias. La función estructural de este largo parlamento consiste en la recuperación de la historia anterior al presente dramático para conectarla íntimamente con el aspecto ideológico propuesto por la obra en su conjunto. El personaje ofrece de manera escalonada un recorrido por los lugares y las personalidades que lo veneran —desde los príncipes de Alemania hasta los de Italia y Suiza, pasando por Felipe IV, quien le concedió el Toisón de Oro en 1628-, para ostentar su carta de presen- 
tación ante los espectadores que son testigos del cambio que el resentimiento y la megalomanía han provocado en él. La pregunta que se hace ante todos - "¿Yo he de ser vasallo, yo, / siendo quien soy?” (wv. 1633-1634) — habría provocado sorpresa entre el público, conocedor de un Wallenstein diferente que había conseguido grandes éxitos para España, pero es la que finalmente introduce el motivo fundamental de la reunión con los oficiales: su deseo de atentar contra la autoridad imperial para hacerse con la Corona de Bohemia: "que es patria mía, / regio dosel me dispone, / augusta silla me ofrece / en Praga su ilustre Corte: / a Rey me inclina mi estrella" (vv. 1647-1651).

En la obra aparecen numerosas menciones de la influencia que tenía la astrología sobre los movimientos de Wallenstein. La biografía de Mann (1976, pp. 76-85) indica que el general había consultado a Kepler en 1608 para que le hiciera su horóscopo, y que tenía un astrólogo italiano a sueldo (Giovan Battista Senno) que lo acompañaba en sus misiones y estaba con él cuando fue asesinado. Asimismo, Geoffrey Mortimer (2010, pp. 52-67) dedica una sección de su biografía a esta característica de la personalidad de Wallenstein, aspecto conocido por todos cuando se produjo su muerte ${ }^{21}$ y que sus enemigos se habían encargado de explotar y difundir. Los autores supieron manipular esta obsesión por la astrología para diseñar un personaje obstinado que luchaba por conseguir la "augusta silla" porque así lo había decidido el destino; por ello, el Wallenstein que presenta este parlamento insta a los oficiales a unirse a él sin temor, ya que el porvenir está escrito del mismo modo que sus victorias en el campo de batalla.

El plan del general conseguirá rápidamente sus oficiales afines, como el mariscal y el conde, pero también desembocará en una serie de lealtades disimuladas que empiezan con el capitán y el coronel e irán aumentando progresivamente hasta el aislamiento definitivo del protagonista. No sólo Cordón y De Bros prometen fidelidad a Wallenstein después de escuchar sus intenciones, sino que el mismo general, cuando aparece

${ }^{21}$ Wilson (2009) apunta que su interés por la astrología ya se conocía sobradamente en 1627: "Pamphlets appeared claiming his decisions were guided by astrologers' predictions. This was a deliberate fabrication propagated by Maximilian as part of his campaign to get Wallenstein dismissed and was calculated to appeal to Ferdinand's piety. It spread swiftly through diplomatic reports and had gained wide credence by 1633 , assisting the task of those who now sought to remove him again" (pp. 535-536). 
ante el emperador y su hijo, el rey de Hungría, al final del primer acto, se erige como gran defensor de los valores imperiales de Fernando II y Felipe IV. Este fingimiento de lealtades es el motor de la acción dramática y se mantiene hasta el momento en que Wallenstein es asesinado. Cuando el coronel Cordón permite a Wallenstein ocupar su castillo en Egra para que sea "asiento de las armas de / Bohemia" (vv. 1758-1759), se está de nuevo disimulando lealtad, al igual que cuando el checo hace jurar a sus oficiales, quienes tienen por propósito urdir una trampa en la que Wallenstein caiga preso.

El juramento histórico, conocido como el "Juramento de Pilsen”, se realizó durante una reunión de todos los oficiales entre el 11 y el 13 de enero de 1634, organizada por el mariscal von Ilow. Sin embargo, como señala Mortimer (2010, p. 208), el objetivo principal del encuentro era unir a los oficiales para oponerse a la política que el imperio pretendía seguir en la guerra, por la imposibilidad de llevarla a cabo. El mariscal afirmó en la reunión que la corte no otorgaba suficientes recursos para poner en marcha tan grande ejército y se quejó por la falta de reconocimiento a Wallenstein. El checo propuso presentar su dimisión, pero los oficiales, quienes habían invertido mucho dinero en esta guerra, lo convencieron de que continuara. Wallenstein buscaba poner término a la guerra, no un golpe de Estado contra el emperador, como se presenta en El prodigio. Puede pensarse que se tomó demasiadas libertades que no le correspondían, y que esto se tomara por afrenta contra el imperio, aunque también, como indica Cicely Wedgwood (2005, pp. 344-345), pecó de excesiva confianza al pensar que todos los oficiales cumplirían su palabra.

Wallenstein había perdido la lealtad de oficiales cercanos al rey de Hungría, los cuales apoyarían el nombramiento de éste como próximo generalísimo (véase Parker 2006, pp. 127-128). Veit Valentin (1935, p. 159) indica al respecto de tales deserciones que muchos de estos oficiales querían enriquecerse y convertirse en condes y barones, para lo cual tenían que combatir y ganar batallas; la paz, por lo tanto, les servía de muy poco. En tanto, Emilio Beladiez (1967, p. 361) acusa a Ottavio Piccolomini de inventar y exagerar los planes de Wallenstein con el propósito de horrorizar a las personas cercanas al emperador ${ }^{22}$.

${ }^{22}$ Poyntz (1908) también señala el interés de Piccolomini por enriquecerse, y lo califica de "secret enemy", el origen de todos los males de Wal- 
Como señala Robert Bireley (1981, p. 264), el emperador necesitaba conseguir fondos para continuar la guerra y, poco antes de ser asesinado Wallenstein, ya había decidido embargar las propiedades del checo ${ }^{23}$.

El documento que firmaron los oficiales se entendió en Viena como un intento de reunir fuerzas para atacar al emperador. En diciembre, Wallenstein se había retirado con su ejército a Pilsen después de conseguir su última victoria en Steinau, batalla que finalizó con clara victoria ante los suecos y que no se menciona en la obra. Los autores organizan la trama tomando la batalla de Lützen como punto de partida para desarrollar su historia y resaltar que la traición de Wallenstein no consistía en ir contra el imperio para defender la paz, sino para prolongar la guerra y acelerar el proceso de descomposición imperial: "si la guerra dilato / que es lo que ahora pretendo" (vv. 19201921). Para Olivares, sin embargo, el éxito o el fracaso de la monarquía española dependía del resultado de la empresa militar, tal y como destacaba Matías de Novoa (1875), ayuda de cámara del rey, cuando escribió en sus memorias que "en ninguna cosa luce tanto la majestad y poder de un Rey, como en las armas; y ninguna otra le puede hacer mayor, más temido y respetado... que la acción militar" (p. 461). Tanto en la corte española como en la imperial había una necesidad de continuar luchando para mantener el dominio, y, por ende, a ninguno interesaba tanto que la guerra no finalizase en 1634 como a Felipe IV y a Fernando II.

lenstein: "To Piccolomini and men of his stamp the war was their livelihood and their one means of enriching themselves" (pp. 28-29).

${ }^{23}$ Acerca de las tierras de Wallenstein, Kinsky, Ilow y Trčka, BiReley señala: "The confiscation of their lands constituted another major transfer of property in Bohemia. The intent was to use the property to help finance the army. Already in late February Ferdinand had appointed confiscation commissioners to inventory and seize lands of the notorious rebels. But even before the commissioners could act, Ferdinand had decided to whom the properties of the rebels would be assigned. The chief beneficiary of the allotment of lands turned out to be General Gallas; after receiving Wallenstein's two principalities, Friedland and Reichenberg as well as most of the lands of Kinsky, he became one of the greatest landholders in Bohemia. This was to be sure a reward for his part in the whole Wallenstein affair. But other generals had played a scarcely inferior role. Ferdinand's generosity to Gallas seems to have been dictated by the intent to bolster his credit and thus the confidence in the soldiers that Gallas would be able to pay them as Wallenstein had" (p. 266). 
El segundo acto de la obra fortalece la imagen de un Wallenstein psicológicamente débil e inseguro ante la responsabilidad de tomar decisiones, simbolizada en una escena en la que escucha a dos personas que defienden al emperador y realizan un juramento para acabar con el general. Esta situación provoca una enorme angustia en el duque, que se marcha para coger una espada; cuando regresa, se encuentra con el conde y el mariscal, sus dos mayores aliados, y piensa que son ellos quienes pretenden su muerte. Fueron muchas las dudas que pasaron por la mente de Wallenstein durante el invierno de 1633-1634, tras la victoria en Steinau. Graham Martin (1991, p. 341) subraya la influencia que Gundacker von Liechtenstein ejerció en la decisión que tomaría el emperador poco después de que le hiciera entrega de un detallado memorando, Gutachten wegen des Friedlanders, el 11 enero de 1634, en el cual se especificaban los supuestos agravios cometidos por el checo y los actos de traición contra el emperador ${ }^{24}$. El autor se sumaba a lo señalado por Piccolomini y avisaba que el destino de la Casa de Austria podría quedar en manos de Wallenstein y de sus posibles alianzas con potencias enemigas.

Von Liechtenstein indicaba al emperador que Wallenstein no quería tener tropas españolas, pues las consideraba más difíciles de sumar a la insubordinación y, en las conclusiones del informe, no veía otra solución posible que la del cese, pues había demostrado sobradamente su culpabilidad al faltarle el respeto a la Corona imperial: "It is said that last summer he did not defeat the enemy, though he could have... He selected billets according to his caprice rather than need outside the Empire in the Hereditary Lands, contrary to Your Majesty's order" (Wilson 2010, p. 189) ${ }^{25}$. Von Liechtenstein también sugería la necesidad de buscar un reemplazo antes de despedirlo, y creía que Fernando, hijo del emperador, representaba la mejor opción. Para él, ninguna paz era más perjudicial que la que suponía la pérdida de estatus y reputación: "the greatest evil and ridicule such a high potentate can suffer" (p. 191).

${ }^{24}$ Mortimer (2010, pp. 215-216) también analiza la influencia de Von Liechtenstein y advierte que el emperador siguió al pie de la letra las recomendaciones que hacía en su memorando.

${ }^{25}$ Las citas del texto de Gundacker von Liechtenstein, como se sugiere entre paréntesis, corresponden a The Thirty Years War: A sourcebook, compendio útil con gran variedad de documentos que comprenden diversas perspectivas sobre este conflicto y todas sus aristas. 
Wallenstein tenía muchos enemigos declarados, por lo que se hace imposible señalar si todos estos actos procedían de una realidad objetiva o de venganzas personales. Sin ir más lejos, el propio Von Liechtenstein había sido jefe del consejo privado del emperador hasta su sustitución por Hans Ulrich von Eggenberg, hombre con gran influencia y apoyo en España, a petición de Wallenstein en 1626. Hasta qué punto llegaba la conspiración wallenstiniana y comenzaba la confabulación de sus enemigos más acérrimos es una pregunta que todavía queda sin responder.

La jornada tercera comienza después de que el duque llega a Egra el viernes 24 de febrero de 1634, día en que recibe la confirmación oficial de su cese. El emperador había dado orden de informar a los cabos de Pilsen que Wallenstein había sido destituido, para que no le obedecieran y tuvieran vía libre para incumplir el juramento firmado unas semanas antes. De igual forma, Fernando II ordenó que todos los oficiales se pusieran a las órdenes de Galasso, Aldringuer, Piccolomini y Colloredo ${ }^{26}$. $\mathrm{Al}$ estar Gordon a cargo de la ciudad de Egra, Wallenstein le pidió que preparara el castillo para sus hombres e hiciera caso omiso de todas las órdenes que pudiesen llegar del exterior. De las disposiciones del emperador ejecutadas antes de la llegada a Egra, motivo principal de la huida, no se menciona nada en la obra. La ejemplificación de la creciente caída en la que ya se encuentra Wallenstein ocurre cuando pide a los cuatro oficiales que cree más leales que firmen un nuevo juramento de adhesión. Tal y como se representa en la obra, Wallenstein no supo, hasta sus últimos días, que Piccolomini y Gallas estaban en su contra ${ }^{27}$.

El 18 de febrero el emperador había anunciado también la patente de proscripción, mediante la cual se hacía público que Wallenstein era un traidor y se proclamaba su dimisión, pero, al no solicitarse su arresto, no fue enviada a Pilsen (Parker 2006, p. 127 ${ }^{28}$. La que sí llegó fue la autorización del empe-

${ }^{26}$ Véase la carta del 21 de febrero de 1634 del conde de Oñate, dirigida al cardenal infante Fernando (Aldea Vaquero 1986, t. 2, p. 509).

${ }^{27}$ En carta de Saavedra Fajardo a Martín de Axpe, con fecha de 24 de febrero de 1634, le señalaba lo siguiente: "No sabemos más de que este domingo pasado [19 de febrero] estaba Frisland sin saber que Piccolomini y Galaso se movían contra él, antes impaciente de que tardaban” (ibid., p. 41).

${ }^{28}$ Fernando II tomó la decisión el 24 de enero, pero el decreto se mantuvo en secreto hasta el 18 de febrero. 
rador para que arrestaran a todos los supuestos conspiradores y los transportaran a Viena para ser juzgados. No obstante, tal autorización también estipulaba que se ejecutara a los prisioneros si oponían resistencia, lo cual daba la posibilidad de evitarse problemas en caso de que fueran absueltos o condenados a una pena de corta duración, como también se representa en la obra: "en que me advierten que aguarde / ocasión para cumplir el soberano dictamen / del Emperador, que atento / del Duque al traidor alarde, / orden ha dado en común / para prenderle o matarle" (vv. 2590-2596) ${ }^{29}$. El nuevo juramento que el duque propone en la obra se concretó históricamente el 20 de febrero, cuando todavía no habían salido de Pilsen. Sin embargo, los autores sintetizaron la información histórica para facilitar su comprensión y situaron los acontecimientos de las últimas semanas de vida de Wallenstein en el castillo de Egra. Wallenstein solicitó a sus oficiales que firmaran el nuevo documento porque consideraba que su intención de buscar la paz se había malinterpretado, por lo que quería dejar constancia por escrito, con una cláusula específica, de que su propósito no había sido nunca ir contra el emperador (Mortimer 2010, p. 223). Wedgwood (2005, p. 347) señala que fueron varios los oficiales que se negaron a firmar el nuevo documento, incluso con la cláusula mencionada. La obra, sin embargo, mantiene el argumento conspirativo y justifica la firma del documento con el hecho de que el duque ya conocía la deslealtad de hombres a quienes estimaba afines. Es muy probable que los autores, suponiendo que indagaron en fuentes oficiales mientras preparaban la obra, hayan consultado información semejante a la que aparece en la carta de Oñate al cardenal infante Fernando el 21 de febrero:

Se ha ido juzgando y sospechando de las acciones e intentos del Duque de Fritlant y particularmente de la plática que hizo a los generales del ejército cuando el emperador le mandó volviese a socorrer al Duque de Baviera dándole con ella motivo para escribir a Su Majestad Cesárea lo que entonces avisé a V.A. en la Junta que después hizo en Pilzen descubrió más su dañada intención porque si bien la convocó con pretexto de querer renunciar al

29 El emperador dio orden a Gallas de que los oficiales no obedecieran a Wallenstein y de que se absolviera a aquellos que hubieran firmado el primer juramento a la fuerza (carta de Saavedra al conde de Oñate, 17 de febrero de 1634, en Aldea Vaquero 1986, t. 2, p. 35). 
Generalato de las armas ya tenía dispuestos la mayor parte de los cabos y oficiales a anotar que no las dejase protegiéndole y prometiéndole de no querer admitir a otro general a lo que quiso que se obligaren por escrito, y llegó esto a tanta declaración que no quiso consentir en el papel una cláusula en que refrendaban que esta promesa se había de entender en servicio de su Majestad Cesárea, y así la mandó borrar, y hubo sobre ello grandes debates por la instancia que algunos hicieron en que no se omitiere esta cláusula... finalmente lo firmaron sin ella en un gran banquete (Aldea Vaquero 1986, t. 2, p. 508).

El sábado 25 de febrero Wallenstein fue asesinado. En la obra, sin embargo, su muerte ocurre el Martes de Carnaval, que en 1634 acaeció el 28 de febrero ${ }^{30}$. Cordón es el encargado de organizar una fiesta para celebrar tal fecha y tejer una trampa a Wallenstein y sus oficiales probos. Es de imaginar que Calderón y Coello sabían perfectamente que el 25 de febrero no era el día en que se había celebrado el Martes de Carnaval, pero lo hicieron para dar mayor fuerza simbólica y poética al momento en que Wallenstein es ajusticiado. La tradición de la celebración carnavalesca viene marcada por el intercambio de funciones entre el héroe y el fantoche, en la que éste se toma en serio su nuevo papel de importancia. Con la llegada de la medianoche — señalada por el aviso de que "ya caen / los cabellos de la noche" (vv. 2606-2607), como precisa el personaje del capitán-, se transitaba del descontrol propio del carnaval a un período de renovación que rechazaba la inestabilidad con la que el fantoche había mantenido en vilo al imperio, mediante la purificación del alma del individuo que conlleva el inicio de la Cuaresma. Con la muerte del general se confiaba en la venida de mayor firmeza y prosperidad a los territorios imperiales, ejemplificadas en el personaje del capitán quien, en la realidad histórica, no aparece activamente hasta ese momento. Calderón y Coello sintetizan la labor de varios personajes históricos en un solo personaje para dotarlo de mayor profundidad dramática de la que realmente tuvo. Devereux no aparece ni en los testimonios de testigos ni en las cartas y documentos oficiales hasta las últimas horas de ese día. En la última escena, el duque se encuentra solo en su habitación, cuando escucha el llanto de un perro que le sugiere el presagio de algo negativo,

${ }^{30}$ Para conocer la fecha del carnaval de aquel año, he consultado el calendario histórico de Cheney (2000, p. 134). 
última situación que utiliza sus tendencias supersticiosas para conducir su obsesión por conocer el futuro ${ }^{31}$. Es entonces cuando De Bros entra en sus aposentos y asesina a Wallenstein.

Los autores de la obra conocían la información de que había sido el mismo Devereux el que asestó la cuchillada mortal, con una partesana, entre las diez y las once de la noche (Mann 1976, p. 843). Butler, el único oficial histórico de los que planearon la muerte de Wallenstein, nunca aparece mencionado en la obra, a pesar de haber sido quien ideó el plan y a quien se le atribuyó el asesinato en los primeros informes que llegaron a España, y en los que no se hace mención alguna de Devereux. El 2 de marzo, en Milán, el cardenal infante se enteró de las primeras noticias del caso, luego de que Saavedra Fajardo le hiciera constar que había recibido un correo de Gallas, en el que se copiaba un mensaje de Butler: "Habiendo entendido la traición de nuestro General, lo consulté con el Coronel Gordon y, entrando con una compañía en el Castillo desta ciudad, degollé a Frislant, Illoch, Conde de Terzicha y Conde Kinzki" (Aldea Vaquero 1986, t. 2, pp. 47-48). Butler utiliza la primera persona, aunque ni siquiera llegó a entrar en el aposento de Wallenstein cuando se perpetró el asesinato (Mortimer 2010, p. 231) ${ }^{32}$. A pesar de todo ello, Calderón y Coello supieron perfectamente que había sido Devereux quien atravesó el pecho de Wallenstein y optaron por convertir al actor más destacado de ese momento particular en el personaje principal de la obra y en salvador de la causa imperial en la transición entre el carnaval y la Cuaresma ${ }^{33}$.

31 Según señala Geofrrey PArker (2006, p. 127), cada vez que llegaba a una ciudad, ordenaba que mataran a todos los perros y gatos para evitar que hicieran ruido.

${ }^{32}$ En otra carta entre los mismos emisor y destinatario, con fecha de 8 de marzo, se vuelve a mencionar la autoría de Butler: "el Coronel Butler irlandés, cortó, cenando, las cabezas a los cómplices de Frislant y que, pasando luego a su casa la halló cerrada y, rompiendo las puertas, entró en el aposento de Frislant... [y] le acometió con una partesana" (AldeA VAQuero, 1986, t. 2, p. 53). El 18 de mayo, Felipe IV escribe a Oñate para demostrarle la felicidad que le ha traído la muerte de Wallenstein "por el beneficio común de nuestra casa y de toda la religión católica”, y le comunica que le hace merced de una encomienda para Piccolomini, Gallas y Aldringer (GÜNTER 1908, p. 414).

${ }^{33}$ En 1641, en uno de los primeros repasos históricos sobre la muerte de Wallenstein, escrito en un panegírico dirigido a Fernando II cuatro años después de su muerte, Pellicer de Ossau y Tovar considera a Devereux el responsable de asesinar a Wallenstein: "Para ejecutarla [la muerte de Wallenstein], enviaron al Capitán Dobbrocx, caballero irlandés... Llegaron 
El prodigio de Alemania finaliza con el restablecimiento de la autoridad imperial, conseguida por la fidelidad de sus oficiales leales y la aparición del emperador en la escena con el cadáver yacente del conspirador. Tras comprobar que el capitán ha cumplido su misión, nombra a su hijo sucesor de Wallenstein, hecho histórico que no tuvo lugar en ese preciso instante, sino el 27 de abril. Tal nombramiento en los últimos versos de la obra confirma que ésta no pudo estrenarse antes de mayo y sirve para presentar al nuevo "gran defensor de la iglesia" (v. 2690) en una escena que transportaba un episodio de la reciente actualidad europea al teatro madrileño. La escena final aumenta el sentido de derrota en unos y de victoria en otros, sensación que se acentúa con la última intervención del capitán, quien cierra la obra advirtiendo que todos aquellos que osen atentar contra "el honor de la casa de Austria" (v. 2699) terminarán siendo castigados. Aunque el asesinato se produjo el 25 de febrero, la información llegó a Madrid por medio de un correo de Milán el 25 de marzo. Tras conocerse la inesperada noticia, se mandó suspender la representación de la obra hoy desaparecida y empezó a concebirse El prodigio de Alemania como instrumento que eliminaría al Wallenstein presentado hasta entonces y lo convertiría en traidor de España y del emperador. Hieronymus Welsch, viajero alemán que fungiría después como consejero del príncipe de Württemberg, asistió en Madrid a una de las representaciones de la obra perdida durante su estancia de once meses en España, como informa en el capítulo 48 de su libro Wahrhaftige Reiss-Beschreibung, publicado en 1658:

a su aposento, mataron un paje, y prendieron un astrólogo. Salió Vvolstain al estruendo de la puerta, que cayó derribada. El soñoliento entre los desperezos y el miedo abrió una ventana para llamar su guarda, o arrojarse por ella. Mas reconociendo la caída mortal, y la huida imposible, se abalanzó a un soldado para quitarle la alabarda pero diole entonces el Capitán Vvalten Dobborocx la muerte, exaltando con el alma todo el confuso tropel de designios traidores y de embustes mágicos que había consultado y le prometían supersticiosos imperios y reinos" (p. 74). Sydnam Poyntz (1908), oficial imperial cercano a Gallas y Piccolomini, y testigo directo de muchos de los acontecimientos de la vida militar de Wallenstein, también responsabiliza a Devereux del asesinato: "Butler han comaunded Walter Devreux with 6 Halberdiers and a Partizan in his hand to goe up and kill Walleston... Devreux at his comming in cryed $\mathrm{S}$ asa sa Traytour thou must dy and piercied hym with his Partizan on the left side having given hym also two Wounds on the body and one in the necke, hee fell to the ground... gave a great groane as if the Devill had gonne out of hym" (pp. 98-99). 
Es pflegen auch die Spanische Herren ihre Zeit mehrmalen mit Spihlen, und offtermals umb vil und grosses Geld, hinzutreiben, insonderheit aber werden täglich schöne Comödien gehalten, die man umb ein geringes Geld kan zu sehen bekommen. Zu derselbigen Zeit hat es sich begeben, dass an einem Donnerstag man in einer solcher Comödi dess Käyserlich Generals von Friedland und Wallenstein, heroische Thaten, nach dem Böhmischen Krieg und Union-Wesen; item seine Erlassung auff ein Zeitlang und dann die Widerantrettung des Käyserlichen Generalats, auch dass hierdurch die Schwedische Macht gedämpffet und vernichtet worden, agirt, und also darbey seine Person und heroische Kriegs-actiones vil mehr, als in der Warheit es jemals gewesen, erhebt, gross gemacht und also belobt, dass männiglichen in der gantzen Stadt darvon zu sagen wuste. Es seyn aber folgenden Sonnabend, mit der ordinari Post von Wien, nachvermeldte Avisen einkommen, nehmlichen [da inforrmación sobre el asesinato de Wallenstein] ...Umb solcher einkommenen Zeitung willen hat man die obvermeldte Comödi, von dem General Friedlaender, (so den folgenden Sonntag wider gehalten werden sollen) freylichen nicht mehr halten dörffen, sondern es ist sein Lob in die allergröste Schmach und Verachtung veraendert worden (pp. 251-253).

Parece bastante evidente que Welsch se refería a la representación de la obra desaparecida sobre Wallenstein escrita por Calderón y Coello. Las palabras del alemán acerca de esta obra ofrecen una imagen de gran popularidad del general checo en la ciudad de Madrid, igual que hiciera Monanni, y dan testimonio de su cancelación luego de confirmarse el deceso. La nueva caracterización de Wallenstein y su posterior caída construyen una imagen de la fuerza imperial, presentada públicamente como un ejercicio deliberado de autoproyección, que pretendía asegurarse una opinión positiva sobre la participación de los ejércitos españoles en los diferentes conflictos de la guerra, tal y como ocurriera con el resto de obras de arte patrocinadas por el Estado y de temática semejante. El caso de El prodigio de Alemania difiere de éstas en que su propósito consistía en rectificar la representación del personaje responsable del triunfo que había supuesto la muerte de un rey enemigo, y cuya batalla victoriosa se había llevado a cabo con una escenificación que daba la oportunidad a los espectadores de compartir la gloriosa experiencia. El triunfo en Lützen había renovado el optimismo con respecto al futuro en la guerra, a tal punto que la noticia llegó a Madrid el 26 de diciembre de 1632 y fue celebrada con 
luminarias y un Te Deum en la Capilla Real (León Pinelo, s.f., ff. 393v-394r). A partir de 1633, Olivares se dedicará a ilustrar los triunfos nacionales de diversas formas: mantener la reputación internacional de España conllevaba el establecimiento de imágenes propagandísticas por las que el conde-duque se exhibía como la autoridad que resolvía los problemas que creaban los enemigos del imperio.

El 18 de mayo de 1634, Felipe IV reconoce ante Castañeda, embajador real en Viena, que "con la muerte de Fridlant nos ha desembarazado Dios de una de las dificultades que se os ofrecían en lo de la liga, y sin duda de la mayor" (Günter 1908, p. 414). El monarca se alegraba de su muerte a pesar de haber luchado hasta el último momento para convencerlo de que se uniese a su proyecto. En la representación de El prodigio no interesaba dar a conocer que Wallenstein había desestimado unirse a la lucha contra los franceses, hecho que se mantuvo en gran secreto en la obra, sino que quería convertirse en rey de Bohemia pasando por encima de todos, algo más directo y fácil de representar en el escenario y que repetía las acusaciones que se producían en Viena. La posición de Wallenstein — decidido a buscar la paz por sus propios medios- y las intenciones de Felipe IV y Olivares no concordaban, motivo por el cual la obra se carga de un fuerte tono propagandístico que justifica el asesinato de un general acusado de conspirador pocas semanas después de haber sido el centro de otra obra en la que se alababa su destreza militar. La obra plantea una problemática del presente que produce una toma de posición del espectador, de clara conciencia política, y lo dirige convenientemente hacia la indignación y el análisis de esta contradicción en términos favorables y consonánticos con el desenlace de las tramas histórica y dramática.

John Elliott (1985) analiza el uso de la propaganda en la España de Felipe IV y explica que los recursos utilizados para justificar y glorificar el sistema imperante "eran perfectamente susceptibles de resultar contraproducentes y de perjudicar a la misma causa para cuya promoción fueron pensados" (p. 17). La función catártica de El prodigio surge de la exigencia de responder en el presente al cambio de opinión sobre un personaje que representa la dimensión heroica del pasado nacional —en términos de Ruiz Ramón (1971)—, a través de un espacio de mediación basado en una memoria colectiva que persigue entender la relación entre ambos momentos históricos, entre lo que ocurrió entonces y lo que ocurre ahora, y su capacidad 
de subsanar los efectos nocivos de la obra anterior. La imagen que Olivares se había creado en la corte podía malograrse por la equivocación de haber mantenido a Wallenstein en un puesto de tanta relevancia, con lo que se hacía indispensable representar todo lo conseguido cuando el checo fue nombrado generalísimo, para justificar la atención que se le había otorgado en las tablas antes de mostrar las repentinas acciones que convertían su asesinato en una resolución necesaria.

La entrada de España en la Guerra de los Treinta Años se había dado, en gran medida, para recuperar el prestigio que varios representantes de España en el extranjero sintieron haber perdido durante el reinado de Felipe III. Para ellos, la afirmación activa del poder era fundamental para recobrar la supremacía europea y evitar la intromisión de potencias rivales en los intereses de la nación española. Todo ello había contribuido a la caída del duque de Lerma, considerado culpable por las políticas pacifistas promovidas durante su gobierno. Decisivo en su caída fue Baltasar de Zúñiga, embajador en Praga hasta 1617 y consejero de Estado desde 1618, hasta su muerte en 1622, cuando su sobrino Olivares lo relevó en el cargo, ya bajo Felipe IV (Elliott 1989, pp. 117-118).

En un discurso presentado ante el Consejo de Estado en 1621, Zúñiga consideró "desproporcionada" la prolongación de la tregua con los holandeses y animó a Felipe III a terminarla para "restaurar la reputación deslustrada... [puesto que] una monarquía..., cuando ha perdido la reputación, aunque no haya perdido el Estado, será un cielo sin luz, un sol sin rayos, sin espíritu, un cadáver" (Yáñez 1723, p. 116) ${ }^{34}$. Su propósito no debía ser otro que la victoria total, porque "no los sosegaréis sin vencerlos" (p. 118), y recomendaba al monarca "acrecentar los ejércitos, tanto que os hagáis temer" (p. 120). Olivares tomó toda esa manía por la reputación y la forma de entender la situación presente como oportunidad para recuperar el prestigio internacional y conseguir el apoyo necesario con que instaurar los fundamentos económicos y políticos, y llevar tal propósito a cabo. Uno de sus más ambiciosos proyectos fue la construcción del Palacio del Buen Retiro, espacio de recreo para Felipe IV

${ }^{34}$ Zúñiga incluso recomendaba al monarca que no considerara la "falta de dinero" un factor determinante para el aplazamiento (id.). Sin embargo, por la enorme influencia de otros consejeros que se habían opuesto firmemente a la intervención en Bohemia, no fue fácil convencer al monarca de entrar en el recién comenzado conflicto (BRIGHTwELL 1982, p. 117). 
y sede de festejos, cuya construcción comenzó en 1630, y que coincidió con un aumento considerable del programa de mecenazgo real de las artes (Brown \& Elliott 2003, p. 62). En 1632, el embajador de Florencia había percibido una falta de apoyo de la nobleza a las iniciativas de Olivares, manifiesta en la falta de aplausos y en la escasa asistencia a celebraciones y festividades, y destacaba las posibilidades de representar obras de teatro en el nuevo palacio que impresionaran tanto a sus detractores como a los que quisieran contemplar las esplendorosas grandezas alcanzadas bajo su gobierno ${ }^{35}$.

Entre 1633 y 1635 , justo durante las representaciones de las obras centradas en Wallenstein, se decoró el Salón de Reinos del Palacio del Retiro con una serie de doce lienzos que conmemoraban grandes victorias en batallas recientes. El formato que compartían todos estos cuadros representa a un general victorioso, en una posición destacada entre la escenografía, y exalta un sentimiento de presentación teatral muy semejante a las obras mencionadas anteriormente. Toda esta unificación de criterios contribuía a crear opinión y fortalecer la legitimidad de un gobierno necesitado de una mitología oficial fundamentada en la exaltación patriótica. El objetivo primordial de los cuadros, al igual que los dramas históricos como el que se estaba representando sobre Lützen cuando llegó la noticia de la muerte de Wallenstein, consistía en la justificación de un proyecto político y en el enaltecimiento del poder del monarca y su ministro. En 1629, Olivares había ordenado que no se diese licencia para imprimir libros de historia sin la aprobación del Consejo de Estado. La importancia que la historia y su representación pública tenían para el conde-duque queda reflejada en su intervención ante el Consejo de Estado en octubre de 1634, cuando - después de que Franz Cristoph Khevenhüller pidiera consultar el Archivo de Simancas para escribir la historia de la guerra por encargo del emperador- apostilló que "son muchos los descuidos que tenemos, y entre lo demás, que no es el de menor consideración, lo poco que se cuida la historia", y sugirió que se preparase una "historia digna de toda estimación... que con facilidad se podría enmendar y mortificar a los émulos desta Corona, y particularmente los franceses" ${ }^{\text {"6. }}$.

35 ASF: Mediceo del Principato, t. 4959, f. 316; 12 de junio de 1632.

36 Archivo General Simancas (AGS, en adelante): Estado, leg. 2335, 27 de octubre de 1634 . 
Olivares, que siempre había defendido a Wallenstein como el individuo más apropiado para liderar el ejército imperial cuando fue cesado en 1630, lo consideró un traidor por no apoyar la entrada de las tropas del cardenal infante en Flandes, procedentes de Milán. Para mantener la guerra, Olivares había pedido a Wallenstein que "acudiese con seis mil caballos... para el serenísimo Cardenal Infante... Ambas demandas le tuvieron indiferente", según dijera Pellicer de Ossau y Tovar, cronista oficial nombrado por el conde-duque en 1635, en su biografía del general checo publicada en 1639 (f. 31v). El giro de los acontecimientos tras la muerte del general permitió al cardenal infante completar el viaje y llegar a Bruselas —donde sería finalmente nombrado gobernador de los Países Bajos- en noviembre de $1634^{37}$. Don Fernando fue acompañado por Felipe IV hasta Barcelona, circunstancia que resaltaba la importancia de su misión y el apoyo del monarca a su hermano. El fallecimiento de la gobernadora Isabel Clara Eugenia en diciembre de 1633 había creado un vacío de poder que se temía que pudiesen aprovechar los holandeses para comenzar una rebelión, por lo que se debía llegar a Bruselas lo antes posible. Para ejecutar el plan, necesitaban que Wallenstein les concediese la ayuda de una escolta de 4 mil soldados a caballo, pues en los 800 kilómetros entre Bohemia y Bruselas, la mayoría de los lugares se encontraba en manos enemigas (Mortimer 2010, pp. 206-207).

El encargado de pedírselo en persona fue Diego de Quiroga, capuchino cercano al general -Felipe IV lo llama "su amigo" (Günter 1908, p. 352) en carta del 10 de febrero de 1633que llegó a Pilsen el 4 de enero de 1634. Sin embargo, recibió una respuesta negativa a pesar de los pingües beneficios que el mismo Felipe IV le prometía tres días antes de ser destituido por el emperador (Aldea Vaquero 1986, t. 2, p. 402) ${ }^{38}$. En

${ }^{37}$ Los detalles del viaje se recogen en El memorable y glorioso viaje del infante cardenal don Fernando de Austria de Diego de Aedo y Gallart, publicado en Amberes en 1635, con dedicatoria a Olivares.

${ }^{38}$ El monarca autorizaba a Quiroga a ofrecerle nuevas posesiones a fecha de 21 de enero de 1634: "Para atraer al duque de Fritlant... podréis decirle que la promesa que da a entender que viene de su majestad cesárea del Estado de Wirtemberg y el del Lantzgravio no solamente no la contradiré yo, sino que la aprovaré siempre. Demás de esto he resuelto que se le dé el feudo de Ostuni, ciudad a la marina en el reino de Nápoles... por que conozca más los efectos de mi voluntad. Y si pareciere, que para el fin que se desea no bastan los 50.000 florines al mes y alguna anticipación, podréis ofrecer un pedazo de contado..." (GÜNTER 1908, pp. 403-404). 
Viena, la petición de Felipe IV a Wallenstein para que dejara pasar al duque de Feria como avanzadilla del cardenal infante no tuvo una buena acogida (Carrocera 1949, pp. 90-91). En enero, Olivares culpaba a Castañeda "de haber introducido y fomentado el odio expreso del Duque de Friedland" en la corte de Viena y de aprovecharse de que el rey de Hungría quisiera convertirse en nuevo generalísimo ${ }^{39}$. Después del asesinato de Wallenstein, el objetivo que pretendía Madrid de hacer llegar a Flandes al cardenal infante finalmente podría realizarse. El monarca español esperaba que se nombrara nuevo generalísimo a su hermano y reclamaba su potestad para exigir tal cambio; consideraba que, por el gran apoyo económico que ofrecía para la formación de los ejércitos imperiales, le correspondía elegir a la persona encargada de dirigirlos (Günter 1908 , p. 353$)^{40}$.

El hecho de que la noticia de la muerte de Wallenstein llegase a la corte española mientras se estaba representando una obra laudatoria del recién fallecido daba buena muestra de la desconexión entre Madrid y Viena. A finales de 1633, Olivares era el único, junto con Felipe IV, que defendía a Wallenstein y desconfiaba de las intenciones de Castañeda y de las capacidades militares del hijo del emperador, como hizo saber al rey en carta del 28 de diciembre:

[Castañeda] se arrimaba al rey de Hungría y a todos los desconfidentes de Fridland... está, a mi parecer, más que vehemente sospechoso en culpa gravísima de haber introducido y fomentado, en odio expreso al Duque de Fridlant, el que el señor rey de Hungría se haya empeñado en pretender el mando de las armas...

${ }^{39}$ AGS, Estado, leg. 2335, f. 140, Consejo de Estado del 8 de enero de 1634.

40 "A nadie le parecerá injusto que, poniéndose de mi parte lo que se pone para esta liga, tenga prerrogativas aventajadas, si quiera en la autoridad y seguridad de lo que estas armas hubieren obrar" (ibid., p. 414). "Haviendo de pagarle yo, no se debe extrañar [el rey de Hungría] que quiera que mi hermano le mande" (p. 169). El monarca español ya había mostrado su descontento con el emperador a causa de la financiación de los ejércitos y escribió a Castañeda para decirle que "si yo no asistiera a mi tío con lo que le he asistido y asisto, pudiera poner un ejército real en campaña y mantenerle por seis meses; y pues dejo de hacerlo por no faltar a las conveniencias de su majestad cesárea”. Si el emperador no quiere ayudarle económicamente, Felipe IV amenaza con que "no ha de ser posible que yo prosiga con mis asistencias porque habré menester convertirlas en levantar luego nuevo ejército" (pp. 352-353). 
con el poco fundamento y mayor desconveniencia del servicio de V.M. y de la Casa de Austria (Aldea Vaquero 1986, t. 2, p. 472).

Poco antes, en carta del 25 de noviembre, Felipe IV pedía a Castañeda: "aunque las acciones presentes del duque parezcan extravagantes... no se le puede condenar absolutamente sin oírle primero, ni yo mudar de resolución y más volviendo los ojos a la fineza con que por lo pasado ha servido a nuestra augustísima casa" (Günter 1908, p. 398). Wallenstein creía que la entrada de los españoles daría a los franceses la excusa para acceder al imperio, y así lo hizo saber en Viena (Bireley 2014, p. 200). Friedrich Förster (1844, pp. 192-216) consideraba que el fin principal de Wallenstein no era otro que asegurar la paz, en general, y que la estaba negociando con los franceses para bien del imperio. Desde luego, esta iniciativa personal chocaba frontalmente con las intenciones españolas. Tras la victoria de las tropas imperiales en Nördlingen en septiembre de 1634, Holanda comenzó a recibir apoyo económico de los franceses ${ }^{41}$. Las victorias de los españoles obligaron finalmente a Francia a entrar en guerra en 1635, como había previsto Wallenstein, cuya idea de buscar la paz ganaría adeptos tras su muerte, conforme el país galo comenzara a lograr victoria tras victoria.

El uso del adjetivo gloriosa (v. 28), al comienzo de El prodigio de Alemania, para definir la victoria de Wallenstein en Lützen por boca de quien será su asesino, el capitán De Bros, resume la transformación radical que la figura del checo sufrió en la percepción externa de la época. La diversa representación artística de los triunfos había quedado empañada tras el inesperado asesinato y, con ello, la figura de Olivares, debilitada, por negarse a permitir que sus enemigos usaran en su contra el infausto suceso, ahora que se encontraba inmerso en pleno proceso reivindicativo de su legado. Por ello, debía actuar lo antes posible para que todos pudieran entender que lo ocurrido en Egra había sido para bien del imperio y de España, y que el futuro estaba en buenas manos. El prodigio constituía la defensa pública que el propio Olivares hacía de su política, después de que la obra desaparecida tuviera el efecto contrario, pretendido en

${ }^{41}$ Ambas potencias firmaron un tratado en abril de 1634, pocas semanas después del asesinato de Wallenstein, y Francia les suministró dos millones de florines (véase VAN NimWEgen 2010, pp. 234-240). A cambio, Holanda debía prometer que atacaría tanto por tierra como por mar, y que no entraría en negociaciones de paz con España, como harían en 1641. 
un período en el que buscaba establecer un discurso capaz de presentar un reinado plagado de triunfos, y en el que su reputación saliera reforzada de todo ello.

Al mismo Calderón se le encargó escribir El nuevo palacio del Retiro, auto sacramental que se representó en el nuevo edificio el día del Corpus Christi de 1634 (15 de junio) en una fecha que suponemos cercana al estreno de El prodigio, en el que Felipe IV se transformaba en Cristo, y Olivares en el Hombre, y que se erigía en un claro empleo del teatro para proyectar una imagen positiva de la realeza. La presentación de esta obra, señala Manuel Delgado (2002), tuvo como objetivo llevar a cabo "una apología del recién construido palacio en contra de sus numerosos detractores, los cuales lo consideraron desde un principio como algo extravagante, construido a expensas de los impuestos y gabelas del pueblo" (p. 733). Ambas obras procuraban divulgar la imagen de un rey y un valido victoriosos como evidente ejercicio de autoprotección que nos sirve para vislumbrar la forma en que querían ser considerados en ese preciso momento, y la manera como pudieran afectarles los cambios futuros.

El prodigio recupera la reputación herida, ese concepto que Olivares discutió en profundidad tanto con su tío como con su consejero y mentor Saavedra Fajardo, que se convirtió en su confesor y capellán de confianza durante la década de 1630, período durante el cual puso sus dotes intelectuales al servicio de la monarquía. En 1631, Saavedra dedicó a Olivares sus Introducciones a la política, una doctrina de gobierno basada en la Política de Aristóteles, y en 1633, viajó a la corte de Baviera con un triple propósito: conseguir el apoyo de Maximiliano I para la causa española en Europa, evitar conflictos entre éste y Wallenstein, y acercar a ambos al rey de Hungría (Aldea Vaquero 1986, t. 2, p. xxii). El objetivo principal detrás de todo era permitir que el cardenal infante llegase a Flandes, pues se consideraba que no hacerlo suponía una falta de respeto tanto a la monarquía como al imperio ${ }^{42}$. En Ideal de un político

${ }^{42}$ El 4 de octubre de 1633, Felipe IV escribía a Saavedra para que continuara insistiéndole a Wallenstein a este propósito: "Continuareislo así de aquí adelante procurando mantener al duque en la confianza que conviene y os he encargado, ofreciéndole de nuevo muy buena correspondencia de mi parte, y que en señal de esto y de lo que me he condolido de la estrecheza en que me avisáis le ha puesto la continuación de la guerra en sus Estados, he resuelto asistirle con diez mil escudos cada mes por un año... con esta ocasión habéis de procurar negociar con ese duque, que asista al cardenal 
cristiano, publicado en 1640 —dividido en cien empresas, cuyo primer esbozo habían sido las Introducciones-, Saavedra aconsejaba: "Aun cuando se ve a los ojos la ruina de los Estados, es mejor dejarlos perder que perder la reputación, porque sin ella no se pueden recuperar" (empresa 31; 1789, p. 372). Como ya creía Von Liechtenstein, la paz se consigue por medio de la guerra, y Saavedra, consciente de ello, acusaba a Wallenstein con el duque de Feria de no pretender colaborar en ese propósito a su llegada a los Países Bajos, que de su asistencia había poco que fiar (carta del 16 de diciembre de 1633, en Aldea Vaquero 1986 , t. 2, p. 197) y que sus estrategias parecían más bien arteras o, cuando menos, desafortunadas: "quiere dejar tomar pie al enemigo en estos Estados, pues no le ha dejado un hombre y ha enviado a las Austrias cuatro tercios y un regimiento, pudiendo dejarlas más seguras" (carta del 11 de diciembre de 1633; ibid., p. 192). En las recomendaciones de esta misma empresa, Saavedra diserta sobre la conexión que hay entre la reputación y el miedo que los demás sienten hacia sus posibilidades, puesto que

En la majestad real no hay más fuerza que el respeto, el cual nace de la admiración y del temor, y de ambas la obediencia... ¿Qué otra cosa es la reputación sino un ligero espíritu encendido en la opinión de todos, que sustenta derecho el cetro?... Esta reputación obra mayores efectos en la guerra, donde corta más el temor que la espada, y obra más la opinión que el valor (empresa 31; 1789 [1640], p. 370).

La función didáctica de El prodigio no era otra que la de presentar una lección que sirviera para sostener la reputación del poder de Olivares y convencer a los espectadores de la estabilidad de la posición española en la guerra mediante el mantenimiento de la ilusión generada por las demás obras, ideadas para proyección de la autoridad del valido dentro del Estado ante la pérdida de credibilidad que le podía provocar el asesinato de Wallenstein a manos de soldados imperiales. La estructura de la obra dotaba a los que asistieran a su representación de la capacidad de percibir y juzgar el resultado definitivo de la trama como un acto concluido, y les sugería la coincidencia entre verdad dramática y verdad histórica con un fin que solucionaba

infante mi hermano con lo que habrá menester en su pasaje a Flandes" (GÜNTER 1908, p. 396). 
toda la problemática evocada por las anteriores obras centradas en Wallenstein.

El personaje del capitán pone fin a El prodigio de Alemania resumiendo el motivo de los autores para escribirla: "Y aquí la mano levantan, / Senado, toscos buriles, / que entre láminas retratan / al vivo aqueste suceso, / para castigo y venganza / de todos los conjurados" (vv. 2691-2696). La ejemplaridad de la obra repite el efecto que se pretendía con el diseño del Palacio del Retiro, representa la firmeza de la monarquía española en conjunto con el imperio y construye una imagen pública de los defensores de la Iglesia -Felipe IV, Fernando II y su hijo-que concluye con el nuevo nombramiento de este último y la restauración del statu quo, desenlace habitual en el teatro siglodoresco. Aunque dicho nombramiento no se realizó hasta dos meses después de la muerte de Wallenstein, su inclusión al final de la obra sintetiza el fin último para el que fue concebida: eliminar todo lo dicho sobre Wallenstein en la obra inmediatamente anterior, cancelada y desaparecida; justificar su asesinato como necesario para la supervivencia del imperio; compartir el sentimiento de odio hacia el general con el público asistente, y fortalecer la reputación institucional de la monarquía. Al finalizar la obra con un nuevo generalísimo, Calderón y Coello escenifican una línea de continuidad histórica que conecta el pasado, dispuesto a ser olvidado, con un presente de grandes expectativas.

El drama histórico del Siglo de Oro se caracteriza por su versatilidad a la hora de aplicar enseñanzas en función del tiempo en el que se produce la representación. En El prodigio, la interpretación está supeditada a la liberación de un futuro próspero que se descubre al espectador -implicado activamente en el propósito teatral- como un recorrido glorioso que comienza en el momento en que el capitán, modelo de excelencia reconocido por el emperador, señala el levantamiento de las manos de los autores a quienes el Estado había encargado glorificar el caso y exaltar los valores representativos de la monarquía. El capitán enuncia que la muerte de Wallenstein ha sido un éxito "a la salud del César / y de toda la triunfante / Casa de Austria, de quien es / cabeza Filipo el grande" (vv. 2547-2550). El triunfo histórico queda escrito con la actualización del curso de la guerra y la determinación propagandística de que su influencia ilustrativa continúe vigente tras la conclusión de la obra.

La caracterización que los autores ofrecen del personaje conserva la misma oscuridad que tuvo el verdadero Wallenstein, 
cuyos últimos años de vida contribuyen a desarrollar una imagen enigmática que encierra en su interior diferentes imágenes, a cuál más misteriosa. Tal complejidad no podía más que convertir al checo en un personaje sumamente ambiguo sin demasiado esfuerzo de los dramaturgos, quienes tenían material de sobra en los documentos que pudieron consultar durante la redacción de la obra. Nunca sabremos qué habría sucedido de haber llevado Wallenstein a cabo otras acciones al frente del ejército imperial, o si se hubiera limitado a seguir las órdenes desde Viena y Madrid, en vez de hacer lo que creía más conveniente y de actuar tanto de militar como de estadista. Las continuas negativas del general hicieron que su muerte se tomara en Madrid como un triunfo, un prodigio de liberación que permitía a Olivares tomar el camino que ya había decidido.

El teatro español del Barroco, según Maravall, se encarga de difundir "la imagen de la sociedad que los grupos dominantes y a su cabeza la monarquía se esforzaban por imprimir y conservar en las mentes de todo un pueblo, probablemente para evitar o rectificar ciertas desviaciones críticas" (1990, p. 23). La imagen que representan Calderón y Coello de Wallenstein muestra precisamente una doble faceta: como servidor del emperador, para quien ganó decisivas batallas, y como general falto de lealtad que buscó más su triunfo individual que el colectivo a partir de la batalla de Lützen. Es ahora, a modo de conclusión, cuando volvemos al título ambiguo de la obra que capta perfectamente la visión que la España de 1634 tenía de Wallenstein. El duque, alabado en un teatro madrileño cuando llegó la noticia de su muerte, fue un prodigio admirado incluso por Felipe IV y el conde-duque de Olivares, deseosos de conseguir su participación en la guerra que se planeaba continuar. Lo que finalmente se considerará un "prodigio" será la muerte del general, que permitirá la apertura de optimistas frentes, liderados por nobles, como el hermano de Felipe IV o el hijo de Fernando II, que supieron aprovecharse de la situación y dejar a Wallenstein como un doble prodigio, el del vencedor y el del vencido. Como escribió Pedro Rosete Niño en el soneto "Al salón del Buen Retiro" —con motivo de su inauguración en 1635-, la dualidad con la que fue ideado el palacio simboliza la incipiente conciencia olivariana mediante la cual se transportó al escenario el personaje de Wallenstein: "A este, pues, del León de dos Españas / ya festivo teatro, a sus victorias, / infamando su sangre las campañas, / vendrá el rebelde a tributar dos glorias: / 
una, la espada, para las hazañas; / al pincel otra, para las memorias" (vv. 8-14) ${ }^{43}$.

\section{REFERENCIAS}

\section{Archivos}

Archivio di Stato di Firenze

Archivo General Simancas

\section{Referencias bibliográficas}

Aldea Vaquero, Quintín 1986. España y Europa en el siglo XVII. Correspondencia de Saavedra Fajardo, Consejo Superior de Investigaciones Científicas, Madrid, 2 ts.

Alenda y Mira, Jenaro 1903. Relación de solemnidades y fiestas de España, Sucesores de Rivadeneyra, Madrid, 2 ts.

Arredondo, María Soledad 2011. Literatura y propaganda en tiempos de Quevedo: guerras y plumas contra Francia, Cataluña y Portugal, Iberoamericana-Vervuert, Madrid-Frankfurt/M. (Biblioteca Áurea Hispánica, 67).

Beladiez, Emilio 1967. España y el Sacro Imperio Romano Germánico. Wallenstein, 1583-1634, Prensa Española, Madrid.

Beller, E.A. 1971. "The Thirty Years War", en The new Cambridge modern history. T. 4: The decline of Spain and the Thirty Years War (1609-48/59). Ed. J.P. Cooper, Cambridge University Press, Cambridge, pp. 306-358.

BIRELEy, RoberT 1981. Religion and politics in the Age of the Counterreformation, University of North Carolina Press, Chapel Hill.

Bireley, Robert 2014. Ferdinand II, Counter-reformation emperor, 1578-1637, Cambridge University Press, Cambridge.

Brightwell, Peter 1982. "Spain and Bohemia: The decision to intervene, 1619”, European History Quarterly, 12, 2, pp. 117-141; doi: $10.1177 / 026569148201200201$.

Brown, Jonathan \& John H. Elliott 2003. A palace for the king: The Buen Retiro and the court of Phillip IV, Yale University Press, New Haven, CT.

Calderón de la Barca, Pedro y Antonio Coello 2014. El prodigio de Alemania. Ed. Antonio M. Rueda, Stockero, Miami.

Calvo, Florencia 2002. “"Me harán eterno mármoles y Jaspes». Calderón y Breda. Historia, diálogos y escritura”, en El gran teatro de la historia: Calderón y el drama barroco. Eds. Florencia Calvo y Melchora Romanos, Eudeba, Buenos Aires, pp. 211-226.

43 “Al salón del Buen Retiro”, de Pedro Rosete Niño, fue publicado en 1635, impreso por Diego de Covarrubias y Leyva, guarda mayor del palacio. 
Carrocera, Buenaventura de 1949. "El padre Diego de Quiroga, diplomático y confesor de reyes (1574-1649)”, Estudios Franciscanos, 150, pp. 71-100.

Cartas de algunos padres de la Compañia de Jesús sobre los sucesos de la monarquía entre los años 1634 y 1648 1861-1865. En Memorial Histórico Español, Real Academia de la Historia, Madrid, 19 ts.

Cheney, Christopher R. 2000. Handbook of dates: For students of English history, Cambridge University Press, Cambridge.

Cotarelo y Mori, EnriQue 1924. Ensayo sobre la vida y obras de D. Pedro Calderón de la Barca, Revista de Archivos, Bibliotecas y Museos, Madrid.

De Aedo y Gallart, Diego 1635. El memorable y glorioso viaje del infante cardenal don Fernando de Austria, Juan Cnobbart, Amberes.

Delgado Morales, Manuel 2002. "Alegoría bíblico-eucarística en honor y gloria del conde duque de Olivares en El nuevo palacio del Retiro", en Calderón 2000: Homenaje a Kurt Reichenberger en su 80 cumpleaños. Actas del Congreso Internacional, IV centenario del nacimiento de Calderón, Universidad de Navarra, septiembre 2000. Ed. Ignacio Arellano, Reichenberger, Kassel, t. 2, pp. 729-742.

Díez Borque, José María 2001. "Literatura española de la Guerra de los Treinta Años (1618-1648)”, en Homenaje a Elena Catena. Ed. Antonio Lara García, Castalia, Madrid, pp. 185-214.

Elliott, John H. 1985. "Poder y propaganda en la España de Felipe IV", en Homenaje a José Antonio Maravall, Centro de Investigaciones Sociológicas, Madrid, t. 2, pp. 15-42.

Elliott, John H. 1986. The Count-Duke of Olivares: The statesman in an age of decline, Yale University Press, New Haven, CT.

Elliott, John H. 1989. Spain and its world, 1500-1700: Selected essays, Yale University Press, New Haven, CT.

Förster, Friedrich 1844. Wallenstein's Prozess vor den Schranken des Weltgerichts und des k.k. Fiscus zu Prag, B.G. Teubner, Leipzig.

Fortuño Gómez, VANEssa 2005. "La guerra en los dramas históricos calderonianos", en "Edad de oro cantabrigense". Actas del VII Congreso de la Asociación Internacional de Hispanistas del Siglo de Oro (Robinson College, Cambridge, 18-22 julio, 2005). Ed. Anthony J. Close, con la colab. de Sandra María Fernández Vales, AISO, Madrid, pp. 255-261.

Günter, Heinrich 1908. Die Habsburger-Liga 1625-1635. Briefe und Akten aus dem General-Archiv zu Simancas, Emil Ebering, Berlin.

Justi, Carl 1888. Diego Velázquez und sein Jahrhundert, Cohen \& Sohn, Bonn, 2 ts.

León Pinelo, Antonio s.f. Anales de Madrid hasta el año de 1658, Madrid. [Ms. 18298, resguardado en la Biblioteca Digital Hispánica de la Biblioteca Nacional de España].

Mann, Golo 1976. Wallenstein: His life narrated. Trad. Charles Kessler, Holt, Rinehart \& Winston, New York.

Maravall, José María 1990. Teatro y literatura en la sociedad barroca, Crítica, Barcelona.

Martin, Graham 1991. "Historical fact versus literary fiction: Members of the House of Liechtenstein occurring in Schiller's Wallenstein and Grillparzer's König Ottokar", The Modern Language Review, 86, 2, pp. 337-348. 
Matas Caballero, Juan 2015. “"La fuerza de las historias representada». Reflexiones sobre el drama histórico: los reyes de la historia de España en los teatros del Siglo de Oro", en Tiempo e historia en el teatro del Siglo de Oro. Eds. Isabelle Rouane Soupault y Philippe Meunier, Presses Universitaries de Provence, Aix-en-Provence, http:/ /books.openedition.org/ pup/4553 [consultado el 17 de mayo de 2020].

Mortimer, Geoffrey 2010. Wallenstein: The enigma of the Thirty Years War, Palgrave Macmillan, London.

Novoa, Matías de 1875 [ ca. 1647]. Primera parte de las Memorias de Matías de Novoa, conocida hasta ahora bajo el título de "Historia de Felipe III, por Bernabé de Vibanco", precedida de un Prólogo escrito por el Excmo. Sr. D. Antonio Cánovas del Castillo, en Colección de documentos inéditos para la historia de Espa$\tilde{n} a$, por el marqués de la Fuensanta del Valle y D. José Sancho Rayón, Imprenta de Miguel Ginesta, Madrid, ts. 60 y 61.

Novoa, Matías de 1878 [ca. 1647]. Segunda parte de las Memorias de Matías de Novoa, conocida hasta ahora bajo el título de "Historia de Felipe IV, por Bernabé de Vibanco", en Colección de documentos inéditos para la historia de Espa$\tilde{n} a$, por el marqués de la Fuensanta del Valle, D. José Sancho Rayón y D. Francisco de Zabalburu, Imprenta de Miguel Ginesta, Madrid, t. 69.

Parker, Geoffrey 2006. The Thirty Years' War, Routledge, London.

Pellicer de Ossau y Tovar, José 1639. El seyano germánico Alberto Wenceslao, Eusebio de Wolstein, Duque de Mekelburg, de Fridland, Pedro Lacavallería, Barcelona.

Pellicer de Ossau y Tovar, José 1641. La fama austríaca, o Historia panegírica de la exemplar vida, y hechos gloriosos de Ferdinando segundo..., Sebastián y Jaime Matevad, Barcelona.

Pons de Castelví, Fabricio 1652. Gustavo Adolfo, rey de Suecia, vencedor y vencido en Alemania, Domingo García Morrás, Madrid.

Poyntz, Sydnam 1908. The relation of Sydnam Poyntz (1624-1636). Ed. A.T.S. Goodrick, Royal Historical Society, London.

RINGMAR, ERIK 1996. Identity, history and action: A cultural explanation of Sweden's intervention in the Thirty Years War, Cambridge University Press, Cambridge.

Rodríguez Villa, Antonio 1904. Ambrosio Spinola, primer marqués de los Balbases, Fortanet, Madrid.

Rosete Niño, Pedro 1635. "Al salón del Buen Retiro”, en Elogios al Palacio Real del Buen Retiro escritos por algunos ingenios de España, Imprenta del Reino, Madrid.

Rueda, Antonio M. 2012. "Albrecht von Wallenstein según Calderón y Coello: verdad y poesía en El prodigio de Alemania (1634)", Bulletin of the Comediantes, 64, 1, pp. 89-110; doi: 10.1353/boc.2012.0015.

Ruiz Ramón, Francisco 1971. Historia del teatro español, Alianza, Madrid.

SAAVEdra FAJARdo, Diego de 1789 [1640]. Empresas políticas o Idea de un príncipe político cristiano, Benito Cano, Madrid.

Spang, Kurt 1998. "Apuntes para la definición y el comentario del drama histórico", en El drama histórico. Teoría y comentarios. Ed. Kurt Spang, Ediciones Universidad de Navarra, Pamplona, pp. 11-50.

Sullivan, Henry W. 2010. "The politics of Bohemia and the Thirty Years' War on the Spanish Baroque stage”, Bulletin of Spanish Studies, 87, 6, pp. 723-778; doi: 10.1080/14753820.2010.513097. 
VAlentin, Veit 1935. "Wallenstein, after three centuries", The Slavonic and East European Review, 14, 40, pp. 154-162.

Van Nimwegen, Olaf 2010. The Dutch army and the military revolutions, 15881688, Boydell, Woodbridge.

VEGA, Lope DE 1623. La campana de Aragón, en Decimaoctava parte de las comedias de Lope de Vega Carpio, Alonso Pérez, Madrid, ff. 208r-236r.

Vega García-Luengos, Germán 2001. "Calderón y la política internacional: las comedias sobre el héroe y traidor Wallenstein”, en Calderón y la España del Barroco. Eds. José Alcalá Zamora y Ernest Belenguer, Centro de Estudios Políticos y Constitucionales-Sociedad Estatal España Nuevo Milenio, Madrid, pp. 793-827.

Vega García-Luengos, Germán 2012. "Presencias de Europa en el teatro español del siglo XVII", en Europa (historia y mito) en la comedia española: XXXIII Jornadas de teatro clásico. Eds. Felipe Pedraza, Rafael González Cañal y Elena Marcello, Universidad de Castilla La Mancha, Cuenca, pp. 33-51.

Wedgwood, Cicely V. 2005 [1938]. The Thirty Years War, New York Review of Books, New York.

Welsch, Hieronymus 1658. Wahrhafftige Reiß-Beschreibung..., Rößlin, Stuttgart.

Whitaker, Shirley B. 1978. "The first performance of Calderón's El sitio de Bredâ", Renaissance Quarterly, 31, 4, pp. 515-531.

Wilson, Peter H. 2009. The Thirty Years War: Europe's tragedy, Harvard University Press, Cambridge.

Wilson, Peter H. 2010. The Thirty Years War: A sourcebook, Palgrave, New York.

YÁñez, Juan 1723. Memorias para la historia de Felipe III, Nicolás Rodríguez Franco, Madrid. 